\title{
Oxygen Vacancy-Mediated Interfacial Charge Transfer of Au/ZnO Schottky Heterojunctions for Enhanced UV Photodegradation
}

\author{
Zhufeng Shao $(\mathbb{D}$, Hui Jia, Yufeng Zhang, Xiujuan Yang, Min Zhong, and Chun Chang \\ College of New Energy, Bohai University, Jinzhou, Liaoning 121000, China \\ Correspondence should be addressed to Zhufeng Shao; jinhaiyuan@126.com and Chun Chang; changchun@bhu.edu.cn
}

Received 15 January 2020; Revised 13 June 2020; Accepted 15 June 2020; Published 7 July 2020

Academic Editor: Joaquim Carneiro

Copyright (C) 2020 Zhufeng Shao et al. This is an open access article distributed under the Creative Commons Attribution License, which permits unrestricted use, distribution, and reproduction in any medium, provided the original work is properly cited.

\begin{abstract}
We intend to report an interesting phenomenon related to the different interfacial transfer processes between ellipsoidal-like $\mathrm{ZnO}$ $(\mathrm{E}-\mathrm{ZnO})$ and rod-like $\mathrm{ZnO}(\mathrm{R}-\mathrm{ZnO})$ nanoheterojunctions witness by the nanosecond time-resolved transient photoluminescence (NTRT-PL) spectra. Fristly, E-ZnO and R-ZnO nanoarchitectures were fabricated via facilitating the electrochemical route; and then, they decorated it with dispersed Au nanoparticles (NPs) by the methods of ion-sputtering deposition, constituting Au/E$\mathrm{ZnO}$ and $\mathrm{Au} / \mathrm{R}-\mathrm{ZnO}$ Schottky-heterojunction nanocomplex, which is characterized by SEM, XRD, Raman analysis, and UV-vis absorption spectra. Steady-state photoluminescence and NTRT-PL spectra of as-fabricated Au/E- $\mathrm{ZnO}$ and $\mathrm{Au} / \mathrm{R}-\mathrm{ZnO}$ nanocomposites were probed for interfacial charge transfer process under $266 \mathrm{~nm}$ femtosecond (fs) light irradiation. Simultaneously, a distinct diversification for the NTRT-PL spectra is observed, closely associating with oxygen vacancies $\left(\mathrm{V}_{\mathrm{o}}\right)$, which is confirmed by X-ray photoelectron spectroscopy (XPS) and electron spin resonance (ESR) spectra. Furthermore, Au NPs act as an "annular bridge" and "transit depot" for interfacial charge transfer through local surface plasmon resonance (LSPR) effect and Schottky barrier, respectively, which is identified by NTRT-PL and time-resolved PL (TRPL) decay spectrum. Moreover, this mechanism is responsible for the enhanced photoelectrochemical (PEC) performances of methyl orange (MO) photodegradation under UV light irradiation.
\end{abstract}

\section{Introduction}

Zinc oxide $(\mathrm{ZnO})$, which is a representative II-VI semiconductor with a wide direct bandgap of $3.3 \mathrm{eV}$ and a large excitation binding energy of $60 \mathrm{meV}$, has attracted considerable attention because of its unique optical and electrical properties. Recently, $\mathrm{ZnO}$ has been used as an alternative to $\mathrm{TiO}_{2}$ for photoelectrochemical (PEC) performance due to its nontoxicity, earth-abundant, and high electron mobility efficiency [1]. Meanwhile, $\mathrm{ZnO}$ has a wide application field, including energy conversion and storage, optoelectronics, and environmental remediation [2-4]. At present, various kinds of synthetic methods were adopted for preparing the $\mathrm{ZnO}$ nanostructure, such as sol-gel, chemical vapor deposition, ultrasonic-assisted method, magnetron sputtering, molecular beam epitaxy, and electrochemical deposition [5-10]. Among the preparation methods above, the electro- chemical deposition route provides a better alternative for its facile and feasible operation process. It is well known that the pristine $\mathrm{ZnO}$ semiconductor is intrinsically not a good candidate for PEC implementation, which is limited by light absorption and higher electron-hole $\left(\mathrm{e}^{-}-\mathrm{h}^{+}\right)$pair recombination rate. And these issues are reported to be settled by coupling wide bandgap semiconductors (WBGs) with plasmonic metal nanocrystals (e.g., $\mathrm{Au}, \mathrm{Ag}$, and $\mathrm{Pt}$ ), i.e., $\mathrm{M} / \mathrm{S}$ Schottky contact, as they could improve the concentration of PEC active electrons and facilitate the photogenerated $\mathrm{e}^{-}-\mathrm{h}^{+}$pair separation, which originated from local surface plasmon resonance (LSPR) effect and built-in electric field of Schottky nanoheterojunction, respectively. Researchers have confirmed [11] that pure Au NPs possess greatly photocatalytic activity irradiated by UV light, associated with interband transition from $5 \mathrm{~d}$ to $6 \mathrm{sp}$-band. We are inclined to believed that the PEC performance of $\mathrm{Au} / \mathrm{ZnO}$ 
Schottky-heterojunction nanohybrids would effectively promote mechanisms related with the synergistic effect of energic electron generation and accelerated charge transfer.

The photocatalytic properties of $\mathrm{ZnO}$ can be strongly influenced by introducing native point defects, including oxygen vacancies $\left(\mathrm{V}_{\mathrm{o}}\right)$, zinc vacancies $\left(\mathrm{V}_{\mathrm{Zn}}\right)$, oxygen interstitials $\left(\mathrm{O}_{\mathrm{i}}\right)$, and zinc interstitials $\left(\mathrm{Zn}_{\mathrm{i}}\right)$, especially for $\mathrm{V}_{\mathrm{o}}$. Recently, researchers [12] have reported the $V_{o}$ intrinsic defects could induced visible-light absorption and enhanced PEC activity. Wang et al. [13] concluded that the high concentration of $\mathrm{V}_{\mathrm{o}}$ defects present in $\mathrm{ZnO}$ not only as a trapping levels, but also creates impurity levels near the valence band $(\mathrm{VB})$ of $\mathrm{ZnO}$ and causes bandgap narrowing. Furthermore, Xie et al. [14] have confirmed experimentally that the presence of $\mathrm{V}_{\mathrm{o}}$ can strongly promote interfacial carrier transfer of a $\mathrm{ZnO}$-related nanoheterostructure. Meanwhile, the photocatalytic activities associated with inherent defects for $\mathrm{ZnO}$ are significantly influenced by its different morphologies, including sphere-like, rod-like, flower-like, rice-like, hexagonal disk-like, and other nanostructures [15-19]. Thus, an efficient PEC process for $\mathrm{ZnO}$ can be mediated either by the presence of defect states related to morphology, or intentionally created defects within the bandgap through doping with transition metal ions [20].

Photoinduced interfacial charge transfer is a prevalent phenomenon, which is crucial for semiconductor devices of optoelectronic conversion and photocatalysis. Of permanent interest questions are photogenerated $\mathrm{e}^{-}-\mathrm{h}^{+}$pair separation and recombination process and to what extent native defect states can participate in charge transfer processes at the interface of the heterojunction. Fortunately, transient photoluminescence (PL) spectroscope is a nondestructive and sensitive optical characterization to investigate the fundamental physical properties of $\mathrm{ZnO}$, including inherent energy band and active defects [21]. As investigated in our previous literature, the corresponding PL spectra obtained from $\mathrm{ZnO}$ shows UV and broad visible emission, which are usually assumed to originate from the near-band-edge (NBE) direct recombination and defect-related indirect recombination emission, respectively [22].

In this work, we prepared a series of specimens of ellipsoidal-like and rod-like $\mathrm{ZnO}$ nanoarchitectures decorated with loading controllable Au nanoparticles (NPs) (denoted as $\mathrm{Au} / \mathrm{E}-\mathrm{ZnO}$ and $\mathrm{Au} / \mathrm{R}-\mathrm{ZnO}$, respectively) and investigated their PEC performance-adopted methyl orange (MO) photodegradation under UV light irradiated. The $\mathrm{Au} / \mathrm{ZnO}$ Schottky heterojunction nanocomposites are fabricated via a facile electrochemical deposition and ionsputtering strategy. The loading contents of the Au NPs can be easily controlled by varying the sputtering time. Meanwhile, compared with the conventional defect-doping methods, we provide an effective way to create $\mathrm{V}_{\mathrm{o}}$ in $\mathrm{ZnO}$ via thermal annealing, which is more favorable on preventing from introducing any impurity and preserving the native crystal structures of $\mathrm{ZnO}$. Furthermore, nanosecond timeresolved transient photoluminescence (NTRT-PL) spectra present direct evidence that the interfacial transfer mechanism of the photoinduced electrons in the $\mathrm{Au} / \mathrm{ZnO}$ nanoheterojunction associated with intrinsic defect states. The PL emission of $\mathrm{ZnO}$ is seen to be drastically quenched in the presence of $\mathrm{Au}$ NPs, showing their strong influence on the charge carrier dynamics. To the best of our knowledge, there are only few reports for this interesting phenomenon, which is better understood by introducing competing mechanisms between the photogenerated carrier defect trapping and PEC redox process in the interfaces of the $\mathrm{Au} / \mathrm{ZnO}$ Schottky heterostructure.

\section{Experimental Section}

High-purity reagents were used without further purification for the undoped $\mathrm{ZnO}$ sample synthesis. Ellipsoidal-like and rod-like $\mathrm{ZnO}$ nanoarchitectures were prepared with an electrochemical deposition approach reported in the previous work [23]. The typical synthetic procedure was given as follows: firstly, the fluorine-doped tin oxide (FTO) conductive glass substrates $(1.2 \times 1.5 \mathrm{~cm})$, which with a sheet resistance of $12 \Omega$, were separately cleaned by ethanol and acetone, and then rinsed with distilled water for $5 \mathrm{~min}$ in an ultrasonic cleaner (KQ5200DE). And then, a facile electrodeposition route was applied to synthesize $\mathrm{ZnO}$ nanoellipsoid (E-ZnO) and $\mathrm{ZnO}$ nanorod $(\mathrm{R}-\mathrm{ZnO})$ thin films, respectively. The experiments were conducted in a conventional potentiostatical three-electrode system (CHI600E, CH Instruments Co. Ltd.) at $80^{\circ} \mathrm{C}\left( \pm 2^{\circ} \mathrm{C}\right)$ for $10 \mathrm{~min}$, in which the FTO substrate was used as the working electrode, a Pt plate was applied as the counter electrode and an $\mathrm{Ag} / \mathrm{AgCl}(\mathrm{KCl}$ saturated) was employed as the reference electrode. The electrolyte contained $0.1 \mathrm{M}$ zinc nitrate and $0.1 \mathrm{M}$ hexamethylenetetramine (HMT), and the $\mathrm{pH}$ value of it was approximately 5.5. Lastly, the electrochemical deposition was performed for the E- ZnO and $\mathrm{R}-\mathrm{ZnO}$ samples at a constant potential of $-1.5 \mathrm{~V}$ and $-2.0 \mathrm{~V}$ versus the $\mathrm{Ag} / \mathrm{AgCl}$ reference electrode, respectively. For better crystallization and morphology, the as-prepared $\mathrm{E}-\mathrm{ZnO}$ and $\mathrm{R}-\mathrm{ZnO}$ thin films on the FTO substrates were annealed at $450^{\circ} \mathrm{C}$ and $350^{\circ} \mathrm{C}$ for $30 \mathrm{~min}$ in a tubular furnace, respectively. Well-controlled sample preparations are critical to form nice nanostructures of well-discreted Au NPs on the $\mathrm{E}-\mathrm{ZnO}$ and $\mathrm{R}-\mathrm{ZnO}$ film substrates.

$\mathrm{Au}$ NPs were deposited on the samples of $\mathrm{E}-\mathrm{ZnO}$ and R$\mathrm{ZnO}$ thin films by using an ion-sputtering system, and the isolated Au NPs on the $\mathrm{ZnO}$ films were prepared by thermal annealing in a tubular furnace with different sputtering times $(20 \mathrm{~s}, 40 \mathrm{~s}$, and $80 \mathrm{~s})$, respectively. The highest ramp speed of the temperature in the furnace was $10^{\circ} \mathrm{C} / \mathrm{min}$. When the preset temperature $\left(400^{\circ} \mathrm{C}\right)$ was reached, the samples were annealed for $30 \mathrm{~min}$.

The morphologies and microstructures of the $\mathrm{Au} / \mathrm{ZnO}$ nanocomposites were evaluated by scanning electron microscopy (SEM, Hitachi S4200) operating at accelerating voltage of $15.0 \mathrm{kV}$. A UV-visible (UV-vis) diffuse reflectance spectroscopy (UV-1800, Shimadzu) was applied to study the optical absorption properties of the as-prepared $\mathrm{Au} / \mathrm{E}-\mathrm{ZnO}$ and $\mathrm{Au} / \mathrm{R}-\mathrm{ZnO}$ heterojunctions in air at room temperature. The composition and phase pure of Au NP-decorated $\mathrm{ZnO}$ films were characterized by X-ray diffraction (XRD, Shimadzu XRD-600) using $\mathrm{Cu} K \alpha$ radiation $(\lambda=0.15418 \mathrm{~nm})$. The native defect states of the samples for pristine- $\mathrm{ZnO}$ 
and $\mathrm{Au} / \mathrm{ZnO}$ were examined by $\mathrm{X}$-ray photoelectron spectroscopy (XPS, ESCALAB 250, Thermo Fisher Scientific Ltd.), and the X-ray source was the $\mathrm{Al}$ anode emitting the $\mathrm{K} \alpha(1486.6 \mathrm{eV})$ radiation of $150 \mathrm{~W}$. Crystal structure and chemical bonding states of as-formed $\mathrm{Au} / \mathrm{ZnO}$ Schottky heterojunctions were investigated by using the microRaman spectroscopy system (Horiba JY-HR800) equipped with a confocal microscope with an $\mathrm{Ar}^{+}$laser operating at $532 \mathrm{~nm}$ at a excitation power level of $6 \mathrm{~mW}$ at room temperature. Electron spin resonance (ESR) measurements were performed on a JEOL-TE300 spectrometer operating at an $\mathrm{X}$-band frequency of $9.4 \mathrm{GHz}$.

As described in our previous report [24], a Ti:sapphire femtosecond (fs) laser system (Spectra-Physics) was used to evaluated the steady state and the NTRT-PL spectra for $\mathrm{Au} / \mathrm{E}-\mathrm{ZnO}$ and $\mathrm{Au} / \mathrm{R}-\mathrm{ZnO}$ thin films, respectively. Briefly, the excitation laser beams with wavelength centered at $266 \mathrm{~nm}$, is acquired accordingly by the third harmonic generation (THG) of $800 \mathrm{~nm}$ laser beam through a BBO (beta$\mathrm{BaB}_{2} \mathrm{O}_{4}$, barium metaborate) crystal, with pulse duration of $130 \mathrm{fs}$, repetition rate of $1 \mathrm{kHz}$, and spot size of $1 \mathrm{~mm}$. The PL emission is collected by a spectrometer (Bruker Optics $250 \mathrm{IS} / \mathrm{SM}$ ) coupled with an intensified charge-coupled device (CCD) detector (Istar 740, Andor). Steady-state and transient-state experiments were carried out by adjusting the delay time of the CCD shutter. Laser pulse gives an external trigger signal to open $100 \mathrm{~ms}$ and $0.5 \mathrm{~ns}$ temporal gate of the intensified CCD through a synchronization/delay generator (SDG) and digital delay/pulse generator (DG 535); then, the steady-state and transient PL spectra at different decay times can be recorded by the CCD detector, respectively. Figure 1 gives a schematic diagram of the experimental setup. Simultaneously, the NTRT-PL decay spectra measurement was performed in FLUOROMAX-4 spectrofluorometer in room temperature.

The methyl orange (MO) photocatalytic degradation procedure is as follows: $\mathrm{MO}$ of $5 \mathrm{mg}$ was dissolved in $500 \mathrm{~mL}$ of deionized water to yield a concentration of $10 \mathrm{mg} / \mathrm{L}$, and the mixture was stirred in the dark for 30 min to reach an adsorption-desorption equilibrium. The supernatant was transferred to a quartz cuvette to measure its absorption spectrum, which was exposed to UV irradiation for different durations at a constant temperature of $300 \mathrm{~K}$. The concentration of MO solution was checked every $30 \mathrm{~min}$ using a UV-vis spectrophotometer by monitoring the intensity variation for the characteristic absorption peak at $465 \mathrm{~nm}$.

\section{Results and Discussion}

The surface morphology feature of the pristine- $\mathrm{ZnO}$ and $\mathrm{Au} / \mathrm{ZnO}$ with different sputtering times (20s, $40 \mathrm{~s}$, and $80 \mathrm{~s}$ ) was characterized by SEM as shown in Figure 2 . Figures 2(a)-2(d) present the SEM images for pristine E$\mathrm{ZnO}$ and the three $\mathrm{Au} / \mathrm{E}-\mathrm{ZnO}$ nanocrystals with increasing Au contents; meanwhile, Figures $2(\mathrm{e})-2(\mathrm{~h})$ show the SEM images for pristine $\mathrm{R}-\mathrm{ZnO}$ and the $\mathrm{Au} / \mathrm{R}-\mathrm{ZnO}$ nanocomposites with different $\mathrm{Au}$ sputtering times, respectively. As shown in Figure 2(a), the pristine $\mathrm{ZnO}$ was characteristic of elliptically shaped nanostructures with a major axis length of ca.

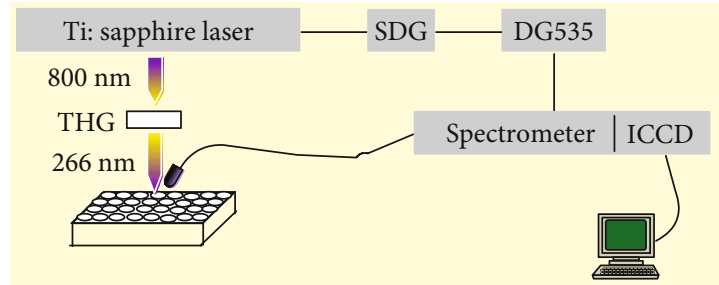

FIGURE 1: Experiment setup of steady-state PL and nanosecond timeresolved transient photoluminescence (NTRT-PL) measurements.

$600 \mathrm{~nm}$ and a minor axis length of ca. $400 \mathrm{~nm}$ under annealing temperature $450^{\circ} \mathrm{C}$. Figures 2(b) and 2(c) show the morphologies of E-ZnO film after gold coating and annealing at $400^{\circ} \mathrm{C}$ with different Au sputtering times (20s and $40 \mathrm{~s}$ ), exhibiting well-isolated Au NPs in inset, which are formed by thermal migration and recondensation of the original continuous gold granular. Figure 2(d) displays the low-magnification SEM image of $\mathrm{E}-\mathrm{ZnO}$-decorated $\mathrm{Au} \mathrm{NPs}$ with sputtering time $80 \mathrm{~s}$, which illustrates the continuous $\mathrm{Au}$ granular film. Figure 2(e) shows that highly aligned bare $\mathrm{R}-\mathrm{ZnO}$ with six planar ends is achieved in a large area, and the average diameter of the nanorods is about $100 \mathrm{~nm}$ under annealing temperature $350^{\circ} \mathrm{C}$. Figures $2(\mathrm{f})$ and $2(\mathrm{~g})$ show the SEM images of the asprepared well-aligned $\mathrm{R}-\mathrm{ZnO}$ arrays decorated with different loadings of Au NPs (20s and $40 \mathrm{~s}$ ), respectively. The length of the as-formed $\mathrm{R}-\mathrm{ZnO}$ ca. is $600 \mathrm{~nm}$ and the width of the crosssection ca. is $60 \mathrm{~nm}$, which is in agreement with the results of SEM observations of Figure 2(e). Meanwhile, the size of the surface-attached Au NPs increased with increasing Au sputtering time, which was homogenously distributed on the $\mathrm{ZnO}$ nanorod arrays. Figure 2(h) shows the high-resolution SEM image of $\mathrm{Au} / \mathrm{R}-\mathrm{ZnO}$ with sputtering time $80 \mathrm{~s}$, which demonstrated distribution of continuous Au NP film.

The crystal structures and composition of as-fabricated pristine $\mathrm{R}-\mathrm{ZnO}$, bare $\mathrm{E}-\mathrm{ZnO}, \mathrm{Au} / \mathrm{R}-\mathrm{ZnO}$, and $\mathrm{Au} / \mathrm{E}-\mathrm{ZnO}$ with loading controllable Au NPs under thermal annealing were investigated by XRD. Figures 3(a)-3(c) show the XRD patterns of $\mathrm{Au} / \mathrm{R}-\mathrm{ZnO}$ heterojunction nanocomposites with different loadings of Au NPs (0 s, 20 s, and 40 s), respectively. Figure 3(a) shows the diffraction peaks of the pristine $\mathrm{R}-\mathrm{ZnO}$ sample at $31.86^{\circ}, 34.49^{\circ}, 36.37^{\circ}, 47.56^{\circ}, 56.73^{\circ}, 62.90^{\circ}, 67.96^{\circ}$, and $72.66^{\circ}$ matched the hexagonal wurtzite structure of $\mathrm{ZnO}$ (JCPDS 89-0511) and indexed to (100), (002), (101), (102), (110), (103), (112), and (004) lattice planes, respectively, which labeled the symbol " $\boldsymbol{m}$." No impurity diffraction peaks were detected in the sample except the signals from the FTO substrate, which are located at $26.41^{\circ}, 51.49^{\circ}$, and $65.53^{\circ}$ and marked the symbol " $\diamond$ " The XRD patterns of the Au/R-ZnO with $\mathrm{Au} \mathrm{NP}$ loading time $20 \mathrm{~s}$ and $40 \mathrm{~s}$ are shown in Figures 3(b) and 3(c), respectively. Besides, for the diffraction peak signals of hexagonal wurtzite $\mathrm{ZnO}$ structure and FTO substrate, a supplementary peak marked with " $\boldsymbol{\nabla}$ " which matched the expected position of the deposited noble metals can be explicitly observed at $38.11^{\circ}$, which was readily assigned to the (111) plane of the face-centered cubic (fcc) Au NPs (JCPDS 04-0784) and strongly indicating Au NPs have successfully been deposited on the $\mathrm{R}-\mathrm{ZnO}$ surface. There were no additional diffraction peaks of other phases 


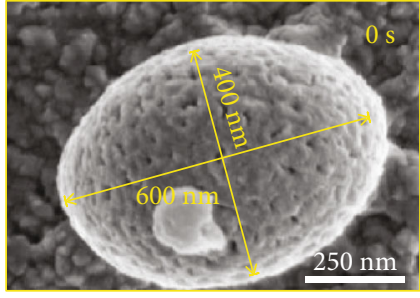

(a)

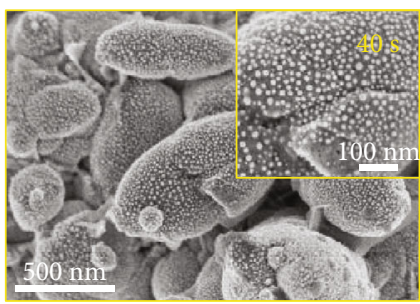

(c)

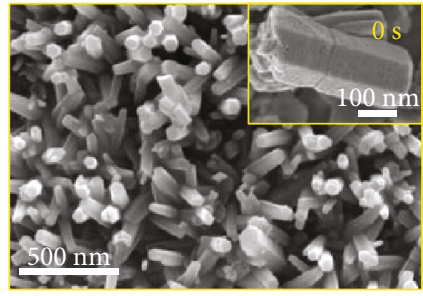

(e)

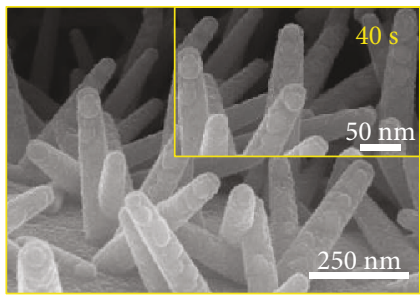

(g)

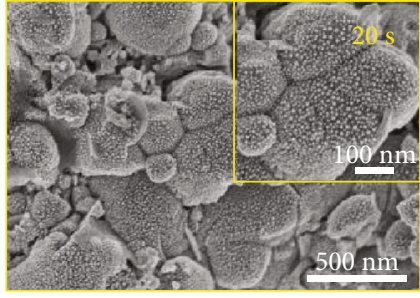

(b)

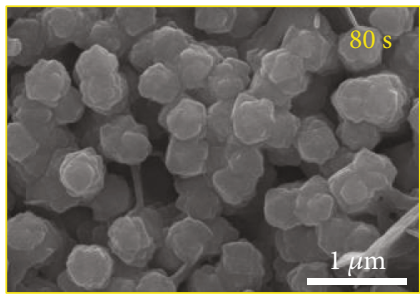

(d)

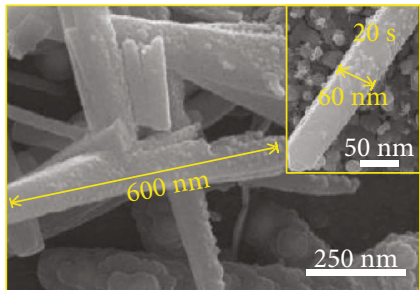

(f)

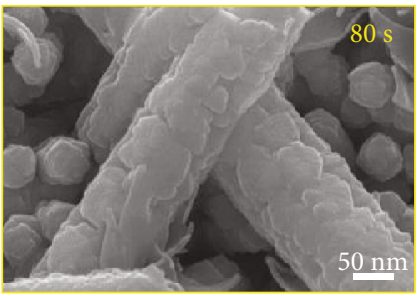

(h)

Figure 2: Morphological characterization of Au/ZnO thin films with different Au sputtering times ( 0 s, 20 s, 40 s, and 80 s), respectively. (a) As-formed pristine ellipsoidal-like $\mathrm{ZnO}(\mathrm{E}-\mathrm{ZnO})$. (b) top-view image of Au nanoparticle- (NP-) decorated E- ZnO with sputtering time 20 s; the inset is an enlarged view. (c) SEM images of Au NP-decorated E-ZnO with sputtering time $40 \mathrm{~s}$, the inset is a magnified view. (d) Surface morphology of Au NP-decorated E- ZnO with sputtering time 80 s. (e) As-prepared pristine rod-like $\mathrm{ZnO}$ (R-ZnO) with enlarged view (inset). (f) Morphology of Au NP-decorated R-ZnO with sputtering time $20 \mathrm{~s}$ and the inset is a magnified view. (g) Side-view image of Au NPdecorated $\mathrm{R}-\mathrm{ZnO}$ with sputtering time $40 \mathrm{~s}$ and the inset is a high-resolution view. (h) High-resolution SEM image of Au NP-decorated R$\mathrm{ZnO}$ with sputtering time $80 \mathrm{~s}$.

or impurities which were observed, demonstrating only the formation of metallic NPs in the ZnO matrix without other oxide phases.

Figures 3(d)-3(f) present the XRD curves of the Au/E$\mathrm{ZnO}$ heterojunction nanocomplex with different sputtering times of Au NPs ( 0 s, 20 s, and 40 s), respectively, diffraction peaks located at $21.53^{\circ}$ and $23.78^{\circ}$ were unknown. Some diffraction peak positions are the same as Figure 3(a) and denoted by the symbol “ $\boldsymbol{\square}$," which corresponds to that of the hexagonal wurtzite $\mathrm{ZnO}$; some diffraction signals are identical to Figure 3(a) and marked with the symbol "»," which is classified as the FTO substrates; other diffraction

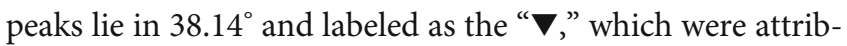
uted to the presence of Au NPs. Furthermore, the average crystallite sizes of all the deposited Au NPs $\left(D_{A u}\right)$ on the
$\mathrm{ZnO}$ matrix can be estimated from the (111) peaks using Scherrer's formula [25]: $D=K \lambda / \beta \cos \theta$, where $K$ is a constant $(0.89<K<1), \lambda$ is the wavelength of the incident $\mathrm{X}$ ray radiation, $\beta$ is the full-width at half-maximum (FWHM) of the diffraction peak, and $\theta$ is the Bragg angle. The $D_{\mathrm{Au}}$ for the samples of $\mathrm{Au} / \mathrm{E}-\mathrm{ZnO} 20 \mathrm{~s}, \mathrm{Au} / \mathrm{E}-\mathrm{ZnO} 40 \mathrm{~s}, \mathrm{Au} / \mathrm{R}-\mathrm{ZnO}$ $20 \mathrm{~s}$, and $\mathrm{Au} / \mathrm{R}-\mathrm{ZnO} 40 \mathrm{~s}$ were calculated to be $15 \mathrm{~nm}$, $43 \mathrm{~nm}, 18 \mathrm{~nm}$, and $45 \mathrm{~nm}$, respectively. It was explicitly indicated that the $D_{\mathrm{Au}}$ increased with increasing Au NP sputtering times from $20 \mathrm{~s}$ to $40 \mathrm{~s}$, which was in good agreement with the SEM observation.

Raman spectroscopy is an efficient avenue to assess the crystal quality and structural defect states on the surface of an as-fabricated sample. Figures $4(\mathrm{a})-4(\mathrm{~h})$ show a typical Raman spectra recorded in the range $280 \mathrm{~cm}^{-1}-750 \mathrm{~cm}^{-1}$ at 

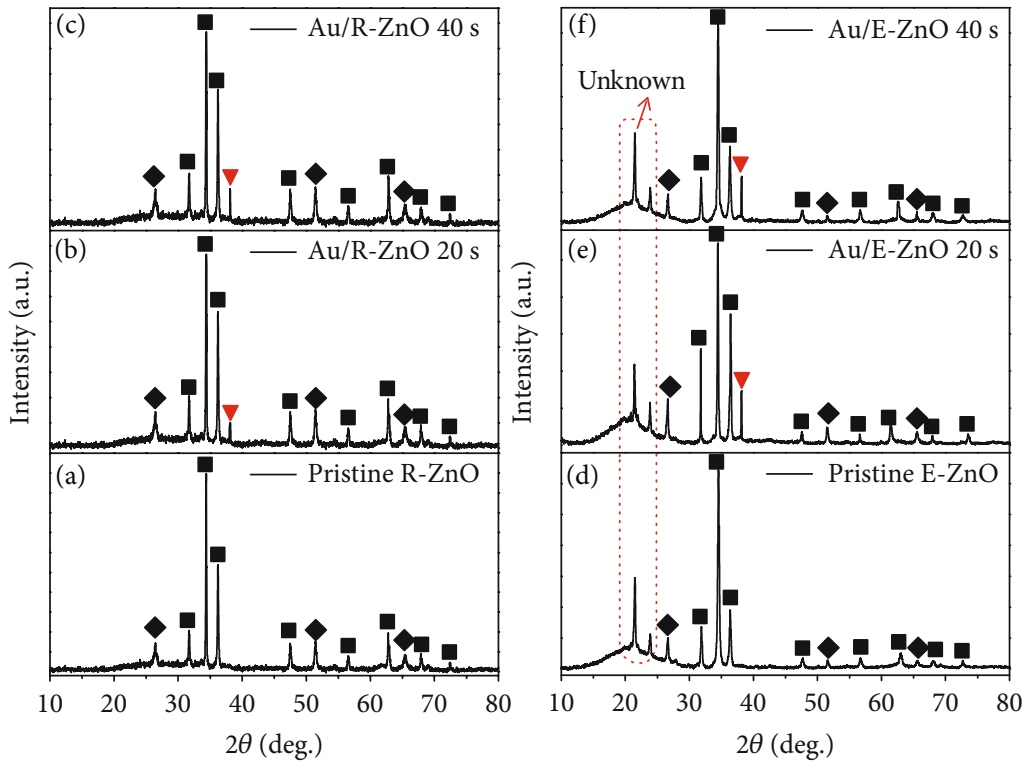

Figure 3: (a-f) X-ray diffraction (XRD) patterns of pristine $\mathrm{R}-\mathrm{ZnO}$, bare $\mathrm{E}-\mathrm{ZnO}, \mathrm{Au} / \mathrm{R}-\mathrm{ZnO}$, and $\mathrm{Au} / \mathrm{E}-\mathrm{ZnO}$ heterojunction nanocomposites for different Au NP deposition times (20s and 40 s), respectively.

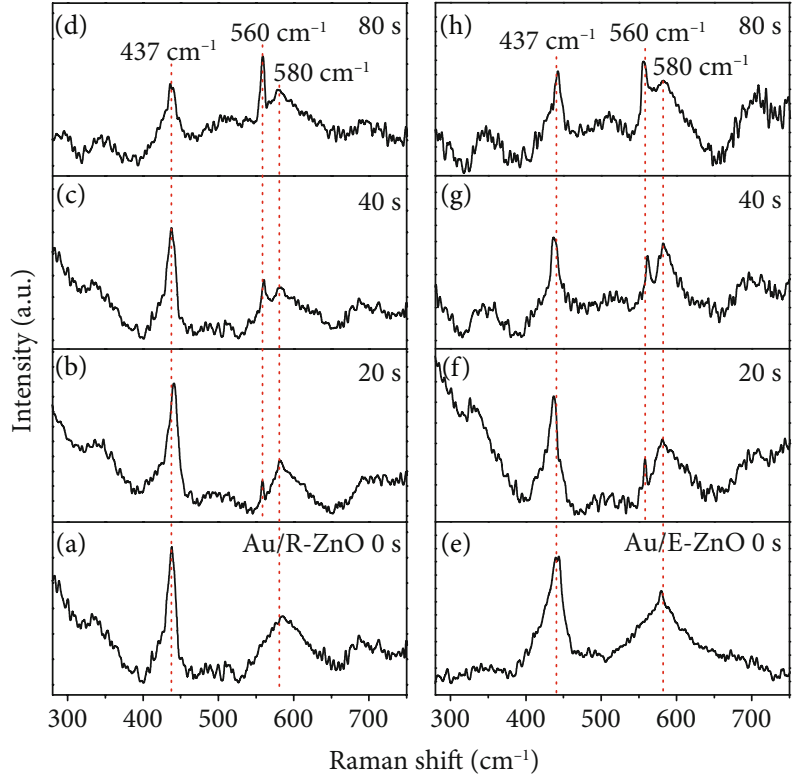

Figure 4: (a-h) Raman spectra of $\mathrm{Au} / \mathrm{R}-\mathrm{ZnO}$ and $\mathrm{Au} / \mathrm{E}-\mathrm{ZnO}$ nanocomposites with different loading Au NPs $(0 \mathrm{~s}, 20 \mathrm{~s}, 40 \mathrm{~s}$, and 80 s), respectively.

room temperature of $\mathrm{Au} / \mathrm{R}-\mathrm{ZnO}$ and $\mathrm{Au} / \mathrm{E}-\mathrm{ZnO}$ Schottky heterojunction nanocomplex with different $\mathrm{Au}$ NP sputtering times $(0 \mathrm{~s}, 20 \mathrm{~s}, 40 \mathrm{~s}$, and $80 \mathrm{~s}$ ), respectively. It is well established that hexagonal $\mathrm{ZnO}$ has characteristic Raman peaks owing to $\mathrm{C}_{6 \mathrm{v}}$ symmetry. Single crystalline wurtzite $\mathrm{ZnO}$ has eight sets of optical phonon modes at the $\Gamma$-point of the Brillouin zone, as follows [26]: $\Gamma=2 A_{1}+2 B_{1}+2 E_{1}+2 E_{2}, A_{1}$ and $E_{1}$ modes could split into two components transverse optical (TO) and longitudinal optical (LO) modes, i.e., $A_{1}{ }^{\mathrm{TO}}, A_{1}{ }^{\mathrm{LO}}, E_{1}{ }^{\mathrm{TO}}$, and $E_{1}{ }^{\mathrm{LO}}$, respectively. The $E_{2}$ mode consists of $E_{2}{ }^{\text {low }}$ and $E_{2}{ }^{\text {high }}$ frequency phonons associated with the $\mathrm{Zn}$ and $\mathrm{O}$ atomic vibrations in $\mathrm{ZnO}$. On the other hand, $B_{1}$ modes are considered silent modes in $\mathrm{ZnO}$, which are composed of $B_{1}{ }^{\text {low }}$ and $B_{1}$ high . In the present investigation, the Raman spectra of Au NP unloaded and loaded R$\mathrm{ZnO}$ and $\mathrm{E}-\mathrm{ZnO}$ samples all showed the remarkable peak at $437 \mathrm{~cm}^{-1}$ is the typical optical phonon $E_{2}$ high mode, corresponding to the band characteristic of the wurtzite phase [27], which is consistent with the XRD analysis. Meanwhile, the peaks at $580 \mathrm{~cm}^{-1}$ ( $E_{1}{ }^{\mathrm{LO}}$ mode) were found to be evident in all Raman spectra, which are associated with the formation of native defects like $\mathrm{V}_{\mathrm{o}}$ and $\mathrm{Zn}_{\mathrm{i}}$ in $\mathrm{ZnO}$ [28]. A new vibration located at $560 \mathrm{~cm}^{-1}$ ( $B_{1}{ }^{\text {low }}$ mode) appeared for the samples of $\mathrm{Au} / \mathrm{E}-\mathrm{ZnO}$ and $\mathrm{Au} / \mathrm{R}-\mathrm{ZnO}$ with different $\mathrm{Au} \mathrm{NP}$ loading times, which was absent for the pristine $\mathrm{E}-\mathrm{ZnO}$ and bare $\mathrm{R}$ $\mathrm{ZnO}$. This peak can be assigned to the newly created defects associated with $\mathrm{Au} \mathrm{NPs}$ attached [29], and its intensity increased with the increase of Au NPs sputtering time. Although, XRD measurement does not probe any strain deformation in the $\mathrm{ZnO}$ crystal lattice, but the incorporation of metal NPs can introduce surface defect states, which originated from the lattice mismatch between metal NPs and $\mathrm{ZnO}$. Further, the $E_{1}{ }^{\mathrm{LO}}$ and $E_{2}{ }^{\text {high }}$ peaks are associated with the lattice oxygen and hence the lowering of its intensity with the increase Au NP amount, which indicates the evolution of $\mathrm{V}_{\mathrm{o}}$-related defects in the lattice. Raman spectra data confirmed the preparation of single-phase hexagonal wurtzite $\mathrm{ZnO}$ structure and formation of defect states in $\mathrm{ZnO}$.

To evaluate the effect of intrinsic defects on the energy gap of the pristine- $\mathrm{ZnO}$ and $\mathrm{Au} / \mathrm{ZnO}$ Schottky heterojunctions prepared under different conditions, the light absorption properties of pristine $\mathrm{E}-\mathrm{ZnO}$, bare $\mathrm{R}-\mathrm{ZnO}, \mathrm{Au} / \mathrm{E}-\mathrm{ZnO}$, and $\mathrm{Au} / \mathrm{R}-\mathrm{ZnO}$ samples were investigated by UV-vis diffuse reflectance spectroscopy. As can be seen from Figure 5 plotted optical absorption curves, the absorption edges of $\mathrm{Au} / \mathrm{R}-\mathrm{ZnO}$ with different deposition times $(0 \mathrm{~s}, 20 \mathrm{~s}, 40 \mathrm{~s}$, and $80 \mathrm{~s}$ ), and $\mathrm{Au} / \mathrm{E}-\mathrm{ZnO}$ with different sputtering times 


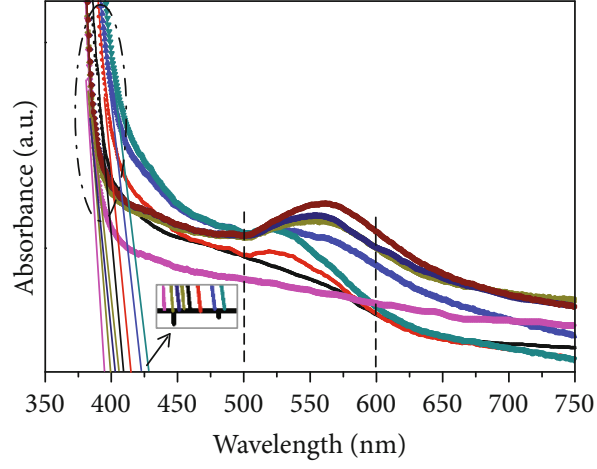

$\begin{array}{ll}-\cdot-\text { Pristine E-ZnO } & -\bullet-\text { Pristine } \mathrm{R}-\mathrm{ZnO} \\ -\cdot-\mathrm{Au} / \mathrm{E}-\mathrm{ZnO} 20 \mathrm{~s} & -\bullet-\mathrm{Au} / \mathrm{R}-\mathrm{ZnO} 20 \mathrm{~s} \\ -\bullet-\mathrm{Au} / \mathrm{E}-\mathrm{ZnO} 40 \mathrm{~s} & -\bullet-\mathrm{Au} / \mathrm{R}-\mathrm{ZnO} 40 \mathrm{~s} \\ ---\mathrm{Au} / \mathrm{E}-\mathrm{ZnO} 80 \mathrm{~s} & -\bullet-\mathrm{Au} / \mathrm{R}-\mathrm{ZnO} 80 \mathrm{~s}\end{array}$

Figure 5: UV-vis diffuse reflectance spectra of pristine $\mathrm{E}-\mathrm{ZnO}$, pristine $\mathrm{R}-\mathrm{ZnO}, \mathrm{Au} / \mathrm{E}-\mathrm{ZnO}$, and $\mathrm{Au} / \mathrm{R}-\mathrm{ZnO}$ heterojunction nanocomposites for different Au NP deposition times $(20 \mathrm{~s}, 40 \mathrm{~s}$, and $80 \mathrm{~s}$ ), respectively. The inset is an enlarged view of absorption edges for pristine $\mathrm{ZnO}$ and $\mathrm{Au} / \mathrm{ZnO}$ with different $\mathrm{Au} \mathrm{NP}$ deposition times (20 s, $40 \mathrm{~s}$, and $80 \mathrm{~s})$, respectively.

$(0 \mathrm{~s}, 20 \mathrm{~s}, 40 \mathrm{~s}$, and $80 \mathrm{~s})$ were $395 \mathrm{~nm}, 399 \mathrm{~nm}, 403 \mathrm{~nm}$, $405 \mathrm{~nm}, 409 \mathrm{~nm}, 415 \mathrm{~nm}, 423 \mathrm{~nm}$, and $428 \mathrm{~nm}$, respectively, corresponding to the bandgap energy $\left(E_{\mathrm{g}}\right)$ of $3.14 \mathrm{eV}$, $3.11 \mathrm{eV}, 3.08 \mathrm{eV}, 3.06 \mathrm{eV}, 3.03 \mathrm{eV}, 2.98 \mathrm{eV}, 2.93 \mathrm{eV}$, and $2.89 \mathrm{eV}$, respectively. The absorption edges believed to ascribe to the NBE excitonic absorption; with the annealing temperature increasing, it is distinctly observed that the band edge red-shifted and broadened as the morphology of $\mathrm{ZnO}$ nanoparticles changed from nanorod to nanoellipsoid, which is in accordance with the previous literature [30]. Furthermore, the decrease in optical bandgap values with increasing loading contents of Au NPs. Chen et al. [31] concluded that $\mathrm{Au}$ NPs could induce excess defects within the bandgap of $\mathrm{ZnO}$ under thermal annealing, thus reducing the valid energy gap. Simultaneously, theoretically and experimentally, we have confirmed that the concentration of $V_{o}$ defects could impactfully modulate the $E_{\mathrm{g}}$ of metal oxide with WBGs attributed to doped noble metal NPs. Light absorption characterization indicated that the presence of $\mathrm{Au}$ NPs can effectively expand the light absorption range of $\mathrm{Au} / \mathrm{ZnO}$ nanocomplex, especially for $\mathrm{Au} / \mathrm{E}-\mathrm{ZnO}$, and improve its PEC performance. We are inclined to believe that the change trend of optical band gaps for prepared $\mathrm{Au} / \mathrm{ZnO}$ samples originated from the concentration variety of $\mathrm{V}_{\mathrm{o}}$ defects, which was in accordance with the Raman spectroscopy investigation. Besides, the enhanced visible light absorption band from $500 \mathrm{~nm}$ to $600 \mathrm{~nm}$ is attributed to the LSPR absorption of Au NPs [32]. The increase absorption intensity is ascribed to size increasing of Au NPs as confirmed in the above SEM observations.

In order to further pinpoint the defect characteristic of $\mathrm{Au} / \mathrm{ZnO}$ hybrid heterojunctions, especially for $\mathrm{V}_{\mathrm{o}}$, the ESR measurements were carried out and the spectra of Au/R$\mathrm{ZnO}$ and $\mathrm{Au} / \mathrm{E}-\mathrm{ZnO}$ with different loading times $(0 \mathrm{~s}, 20 \mathrm{~s}$, $40 \mathrm{~s}$, and $80 \mathrm{~s}$ ) are shown in Figure 6, respectively. It was

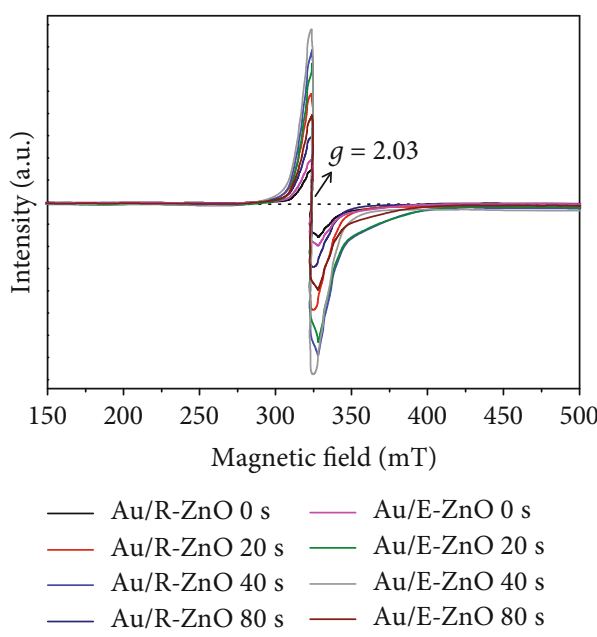

FIGURE 6: Electron spin resonance (ESR) spectra of $\mathrm{Au} / \mathrm{R}-\mathrm{ZnO}$ and $\mathrm{Au} / \mathrm{E}-\mathrm{ZnO}$ Schottky heterojunction nanocomposites with different Au NP deposition times ( 0 s, 20 s, 40 s, and 80 s), respectively.

explicitly observed that all the ESR signals of Au NP undoped and doped $\mathrm{ZnO}$ samples exhibited significant peaks with a $g$ factor of 2.03 (close to the free electron value $g=2.002$ ), which is a characteristic of unpaired electrons trapped on surface $\mathrm{V}_{\mathrm{o}}$ sites [33]. The intensity of the ESR signal for pristine $\mathrm{E}-\mathrm{ZnO}$ was higher than that of bare $\mathrm{R}-\mathrm{ZnO}$, demonstrating that the concentration of $\mathrm{V}_{\mathrm{o}}$ defects was increasing with the increased aspect ratio, which was in good agreement with the results of SEM and UV-vis diffuse reflectance spectra and be useful to the visible-light photocatalytic process. For the $\mathrm{Au} / \mathrm{ZnO}$ samples with different Au NP loading amount, the intensity of the ESR signal peaks were increasing with increased Au NP depositing times from 0 s to 40 s, revealing more $\mathrm{V}_{\mathrm{o}}$ defects could have been induced by doping of noble metal NPs. Moreover, this indicates that there are more superoxide radical anions $\left(\cdot \mathrm{O}_{2}{ }^{-}\right)$generated from surface adsorption oxygen molecules $\left(\mathrm{O}_{2}\right)$ that captured the free electron [34]. For the sample of $\mathrm{Au} / \mathrm{ZnO}$ with loading time $80 \mathrm{~s}$, less concentration of $\mathrm{V}_{\mathrm{o}}$ defect-associated $\cdot \mathrm{O}_{2}{ }^{-}$was observed, owing to its lower specific surface area.

For further evaluation of the chemical states and elemental composition of the as-prepared $\mathrm{Au} / \mathrm{ZnO}$ Schottky nanoheterojunctions, XPS analysis was performed on $\mathrm{Au} / \mathrm{R}-\mathrm{ZnO}$ $20 \mathrm{~s}$ and pristine $\mathrm{R}-\mathrm{ZnO}$ nanocomplex. The survey spectrum result of $\mathrm{Au} / \mathrm{R}-\mathrm{ZnO} 20 \mathrm{~s}$ in Figure 7 (a) demonstrated only peaks that were attributed to $\mathrm{Zn}, \mathrm{O}, \mathrm{C}$, and $\mathrm{Au}$, indicating the sample comprised of $\mathrm{Zn}, \mathrm{O}$, and $\mathrm{Au}$ elements. In addition, the $\mathrm{C} 1 \mathrm{~s}$ peak $(284.0 \mathrm{eV})$ was treated as a reference, which was probably derived from chamber contamination prior to the XPS examined [35]. The detective results were in well concordance with SEM and XRD as elucidated above. High-resolution XPS spectra of $\mathrm{Zn}, \mathrm{Au}$, and $\mathrm{O}$ species were demonstrated in Figures $7(\mathrm{~b})-7(\mathrm{~d})$, respectively. The $\mathrm{Zn}^{2+}$ valence state in the prepared samples was confirmed by the XPS spectra of Zn 2p, which were shown in Figure 7(b). It was observed that the $\mathrm{Zn} 2 \mathrm{p}$ spectrum consists of two binding energy (BE) peaks $1021.9 \mathrm{eV}$ and $1044.9 \mathrm{eV}$ corresponding to the $2 \mathrm{p}_{3 / 2}$ and $2 \mathrm{p}_{1 / 2}$ for pristine $\mathrm{R}-\mathrm{ZnO}$, respectively. 


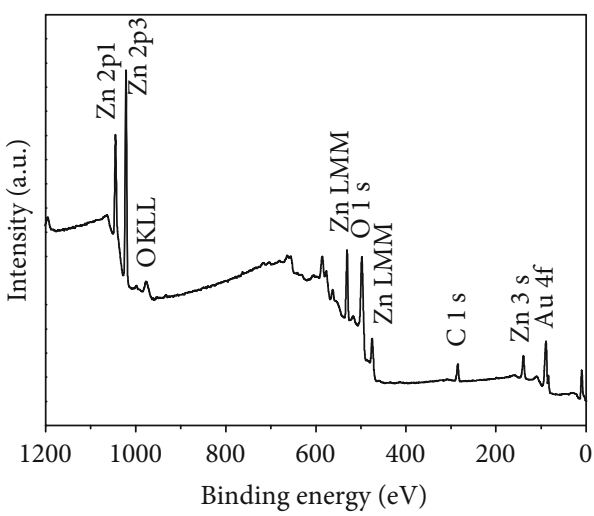

(a)

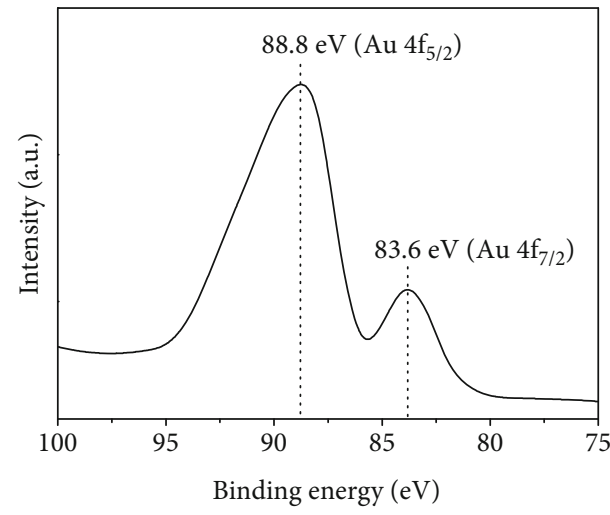

(c)

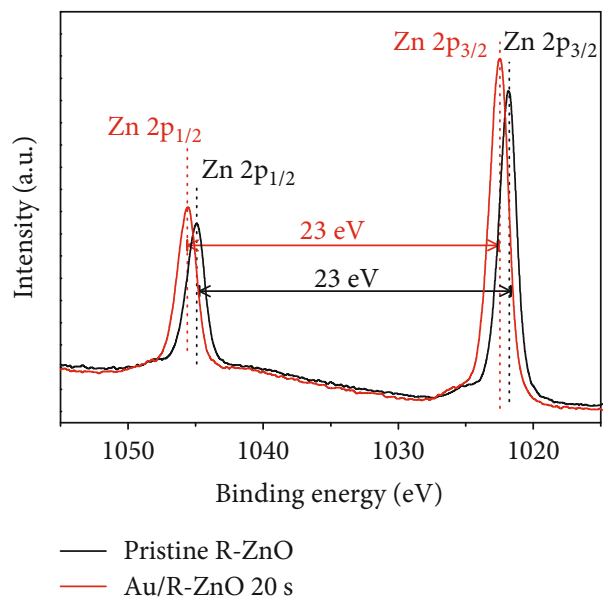

(b)

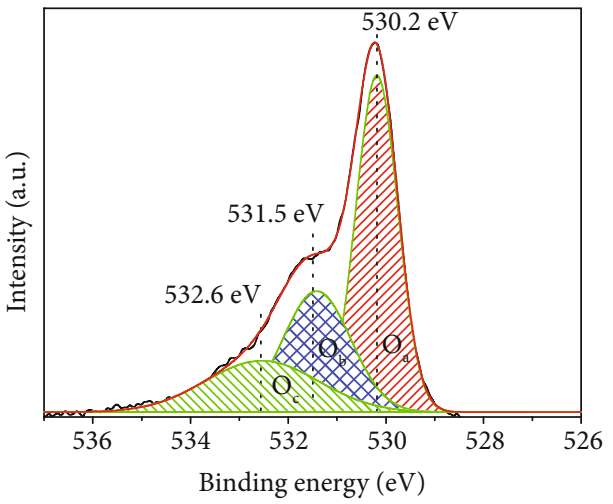

(d)

FIGURE 7: X-ray photoelectron spectroscopy (XPS) characterizations for pristine R-ZnO and Au/R-ZnO 20 s. (a) XPS survey of scan spectrum for $\mathrm{Au} / \mathrm{R}-\mathrm{ZnO} 20 \mathrm{~s}$, (b) Zn 2p of pristine R-ZnO, and Au/R-ZnO 20 s, respectively. (c) Au $4 \mathrm{f}$ for the sample of Au/R-ZnO 20 s. (d) O 1 s core level fitting of $\mathrm{Au} / \mathrm{R}-\mathrm{ZnO} 20 \mathrm{~s}$.

Meanwhile, the core line of $\mathrm{Zn} 2 \mathrm{p}$ for $\mathrm{Au} / \mathrm{R}-\mathrm{ZnO} 20$ s, including $\mathrm{BE}$ of $2 \mathrm{p}_{3 / 2}$ and $2 \mathrm{p}_{1 / 2}$ were located at $1022.2 \mathrm{eV}$ and $1045.2 \mathrm{eV}$, respectively. Compared with the corresponding value of the pure $\mathrm{R}-\mathrm{ZnO}$, the shift of $\mathrm{BE}$ peaks could be ascribed to the reduction of the surface band bending [14]. Furthermore, the $23 \mathrm{eV}$ difference between the two $\mathrm{Zn} 2 \mathrm{p}$ core levels originated from the spin-orbit coupling effect [36]. The XPS spectrum of $\mathrm{Au} 4 \mathrm{f}$ for $\mathrm{Au} / \mathrm{R}-\mathrm{ZnO} 20 \mathrm{~s}$ was presented in Figure $7(\mathrm{c})$. Two significant BE peaks located at $83.6 \mathrm{eV}$ and $88.8 \mathrm{eV}$ were indexed to the electronic states of $\mathrm{Au} 4 \mathrm{f}_{7 / 2}$ and $\mathrm{Au} 4 \mathrm{f}_{5 / 2}$, respectively. Moreover, examination of XPS results indicated that $\mathrm{Au}$ was present in the $\mathrm{Au}^{0}$ state, and further validated that as-formed Au NPs were successfully decorated on $\mathrm{R}-\mathrm{ZnO}$ nanosurfaces. The locations of $\mathrm{Au} 4 \mathrm{f}$ two peaks were shifted to higher BE associated with that of bulk Au, which consisted of $83.1 \mathrm{eV}$ and $87.2 \mathrm{eV}$ corresponding to $\mathrm{Au} 4 \mathrm{f}_{7 / 2}$ and $\mathrm{Au} 4 \mathrm{f}_{5 / 2}$, respectively. This shift phenomenon can be ascribed to electron transport from $\mathrm{ZnO}$ to the $\mathrm{Au}$, which could cause the accumulation of negative charge density on the surface of Au NPs [37]. The fitting results of O $1 \mathrm{~s}$ XPS spectrum for $\mathrm{Au} / \mathrm{R}-\mathrm{ZnO} 20$ s are shown in Figure 7(d). The peaks are decomposed into components by mixed Gaussian-Lorentzian functions and nonlinear squares fitting algorithm. The black solid line is experimental data, and the red solid line is the result of curve fitting. According to the previous literatures [38,39], the main $\mathrm{O} 1 \mathrm{~s}$ core level state can be deconvoluted into three $\mathrm{BE}$ components, including low BE peak $\left(O_{\mathrm{a}}\right)$, medium BE peak $\left(O_{\mathrm{b}}\right)$, and the highest BE peak $\left(O_{c}\right)$ centered at $529.6 \mathrm{eV}-530.3 \mathrm{eV}$ (red oblique line), $531.4 \mathrm{eV}-532.1 \mathrm{eV}$ (blue cross oblique line), and $532.6 \mathrm{eV}-533.4 \mathrm{eV}$ (green oblique-line), respectively. The $\mathrm{O}_{\mathrm{a}}$ is ascribed to $\mathrm{O}^{2-}$ ions in the $\mathrm{ZnO}$ hexagonal lattice, which well coincide with the XRD and Raman measurement; while the $O_{\mathrm{b}}$ is related to $\mathrm{O}^{2-}$ in the $\mathrm{V}_{\mathrm{o}}$ region within the matrix of $\mathrm{ZnO}$; the $\mathrm{O}_{\mathrm{c}}$ is usually associated with the presence of loosely bound oxygen atoms on the surface of $\mathrm{ZnO}$.

To gain more insight into the concentration of $\mathrm{V}_{\mathrm{o}}$ for the samples of $\mathrm{Au} / \mathrm{E}-\mathrm{ZnO}$ with different $\mathrm{Au} \mathrm{NP}$ deposition times $(0 \mathrm{~s}, 20 \mathrm{~s}, 40 \mathrm{~s}$, and $80 \mathrm{~s})$, the core level states of $\mathrm{O} 1 \mathrm{~s}$ were investigated by XPS as shown in Figures $8(\mathrm{a})-8(\mathrm{~d})$, respectively. As stated earlier, the $\mathrm{O} 1 \mathrm{~s}$ spectra of the $\mathrm{Au} / \mathrm{E}-\mathrm{ZnO}$ samples could be described as the superposition of three peaks by mixed Gaussian-Lorentzian distribution and Shirley-type background subtraction by using XPS Peak Fit software. The black solid and red solid lines are experimental and curve fitting data, respectively. Similarly, the main O $1 \mathrm{~s}$ core level state can be deconvoluted into three BE peaks denoted as $O_{\mathrm{a}}$ (green curve), $O_{\mathrm{b}}$ (blue curve), and $O_{\mathrm{c}}$ (gray 


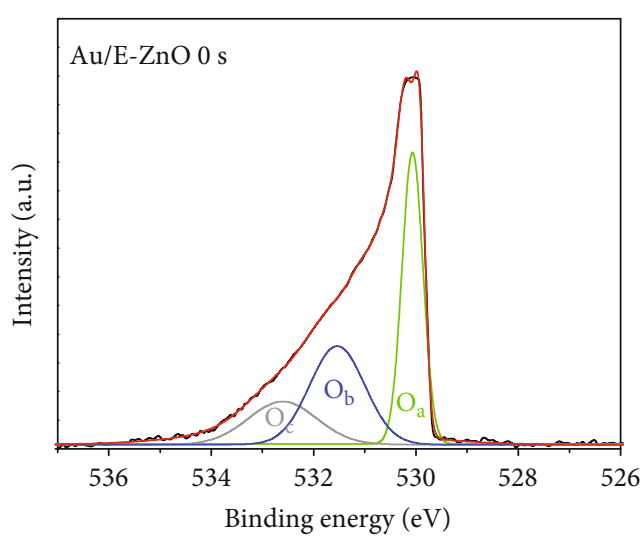

(a)

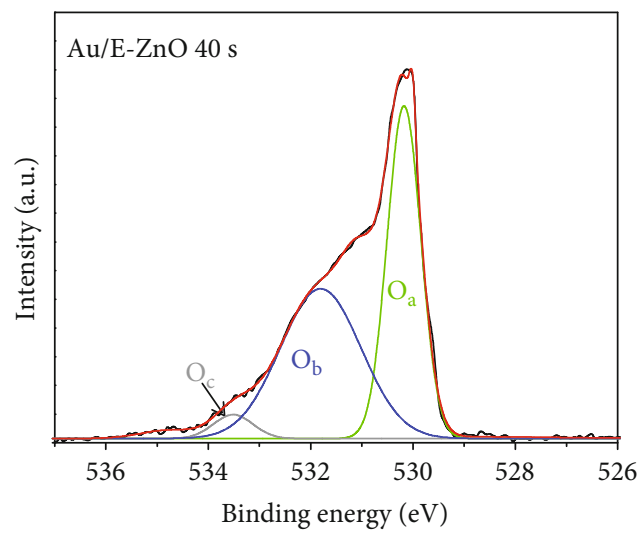

(c)

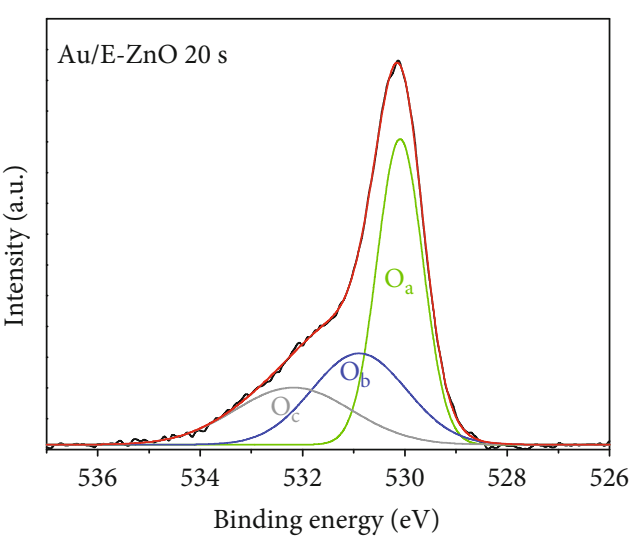

(b)

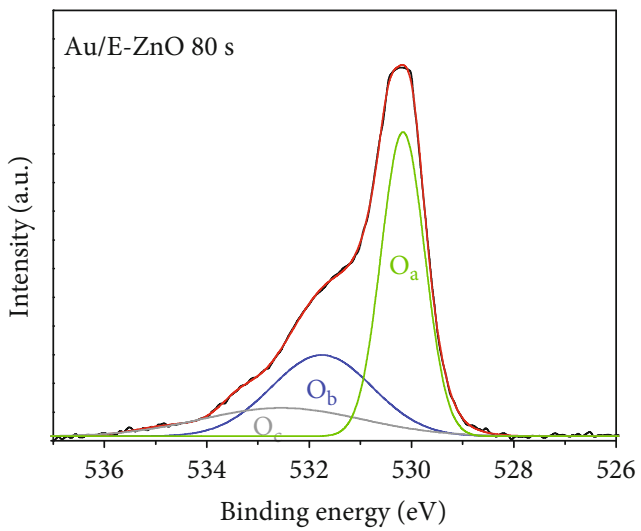

(d)

FIgure 8: (a-d) O $1 \mathrm{~s}$ core level fitting of XPS spectra for Au/E-ZnO Schottky heterojunction nanocomposites with different loading times $(0 \mathrm{~s}, 20 \mathrm{~s}, 40 \mathrm{~s}$, and $80 \mathrm{~s})$, respectively.

curve), which correspond to the lattice oxygen, oxygen deficient, and loosely bound oxygen, respectively. It is believed that the surface area of $O_{\mathrm{b}}$ is connected to the variations in the concentration of $\mathrm{V}_{\mathrm{o}}$ [14].

Therefore, we can obtain the concentrations of $\mathrm{V}_{\mathrm{o}}$ for $\mathrm{Au} / \mathrm{E}-\mathrm{ZnO}$ with different $\mathrm{Au}$ loading amount associated with the surface area ratios (SAR) of $O_{b} /\left(O_{a}+O_{c}\right)$ and detailed descriptions as shown in Table 1. It is observed that the area ratio value of $\mathrm{Au} / \mathrm{E}-\mathrm{ZnO} 40 \mathrm{~s}$ sample is explicitly greater in the $\mathrm{Au} / \mathrm{E}-\mathrm{ZnO}$ samples; the SAR values were increasing with increased Au NP loading times from $0 \mathrm{~s}$ to $40 \mathrm{~s}$, as Table 1 shows, while the area ratio of $\mathrm{Au} / \mathrm{R}-\mathrm{ZnO}$ $20 \mathrm{~s}$ is $49.5 \%$, less than that of $\mathrm{Au} / \mathrm{E}-\mathrm{ZnO} 20 \mathrm{~s}$ (53.8\%), owing to the $\mathrm{E}-\mathrm{ZnO}$ possessing more specific surface area. It illustrates that the concentration of $\mathrm{V}_{\mathrm{o}}$ in $\mathrm{Au} / \mathrm{E}-\mathrm{ZnO}$ samples were increased when decorated with more Au NP deposition; this result is consistent with the former conclusion of Raman and ESR analyses.

The PL emission technique has been widely used to reveal the electronic construction of intrinsic surface defects and probe for understanding the surface radiative recombination processes in which photoexcited $\mathrm{e}^{-}-\mathrm{h}^{+}$pairs take part, i.e., primary processes in photocatalysis. Figures 9(a)-9(d) demonstrated the steady-state $\mathrm{PL}$ spectra of the pristine $\mathrm{ZnO}$ and $\mathrm{Au} \mathrm{NP}$-decorated $\mathrm{ZnO}$ with different depositing times $(20 \mathrm{~s}, 40 \mathrm{~s}$, and $80 \mathrm{~s})$ in ambient condition at room tempera-
TABLE 1: The surface area ratios of $O_{b} /\left(O_{a}+O_{c}\right)$ for $\mathrm{Au} / \mathrm{ZnO}$ with different $\mathrm{Au}$ NP deposition times.

\begin{tabular}{lc}
\hline Sample codes & Surface area ratios of $O_{\mathrm{b}} /\left(O_{\mathrm{a}}+O_{\mathrm{c}}\right)(\%)$ \\
\hline $\mathrm{Au} / \mathrm{R}-\mathrm{ZnO} 20 \mathrm{~s}$ & $49.5 \%$ \\
$\mathrm{Au} / \mathrm{E}-\mathrm{ZnO} 0 \mathrm{~s}$ & $39.3 \%$ \\
$\mathrm{Au} / \mathrm{E}-\mathrm{ZnO} 20 \mathrm{~s}$ & $53.8 \%$ \\
$\mathrm{Au} / \mathrm{E}-\mathrm{ZnO} 40 \mathrm{~s}$ & $63.3 \%$ \\
$\mathrm{Au} / \mathrm{E}-\mathrm{ZnO} 80 \mathrm{~s}$ & $47.3 \%$ \\
\hline
\end{tabular}

ture with excitation wavelength of $266 \mathrm{~nm}$, respectively. In the detected spectral region, the integration time of steadystate PL was $100 \mathrm{~ms}$. As illustrated in Figures 9(a) and 9(b), steady-state $\mathrm{PL}$ emission spectra for $\mathrm{Au} / \mathrm{E}-\mathrm{ZnO}$ nanoheterojunctions with different loading times $0 \mathrm{~s}, 20 \mathrm{~s}, 40 \mathrm{~s}$, and 80s, respectively are shown. Emission behaviour of pristine E$\mathrm{ZnO}$ was plotted, and the main profile of the PL spectrum can be deconvoluted into four categories, i.e., UV emission band and different visible emission bands, as shown in Figure 9(a). The sharp emission located at $390 \mathrm{~nm}$ (UV emitted) be pertained to NBE photogenerated electron direct transition recombination of $\mathrm{ZnO}$ between the conduction band (CB) and the VB [40], which is in accordance with $\mathrm{ZnO}$ bandgap energy (ca. $3.23 \mathrm{eV}$ ). Meanwhile, the visible PL emission band was decomposed into three Gaussian 


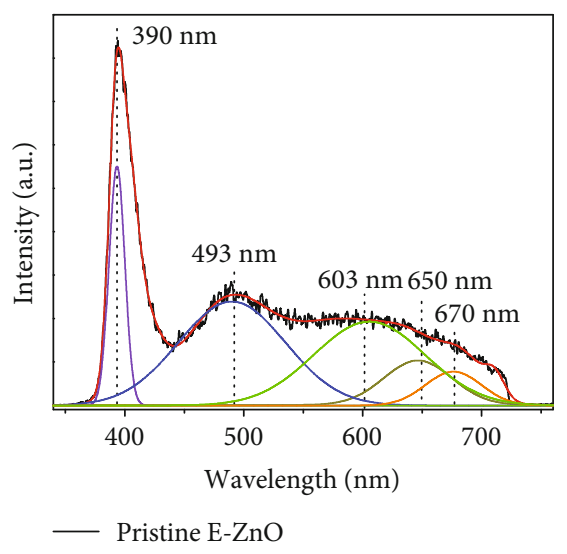

(a)

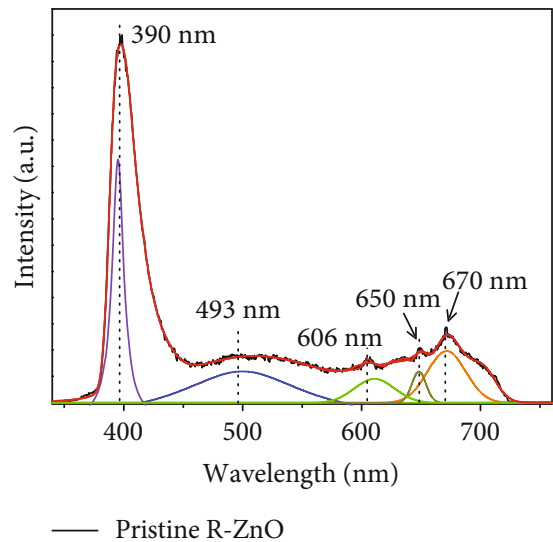

(c)

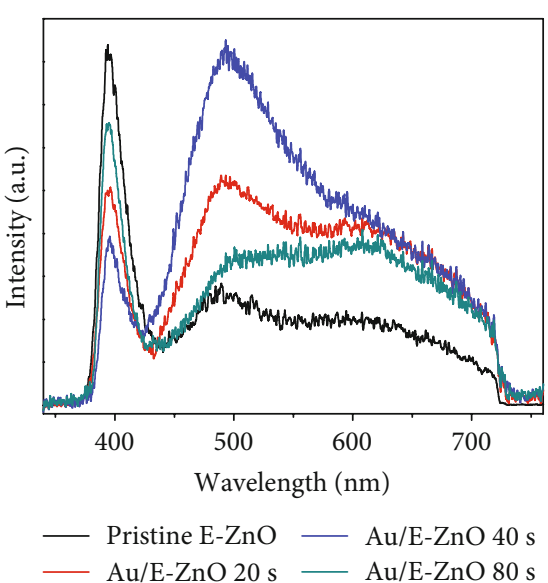

(b)

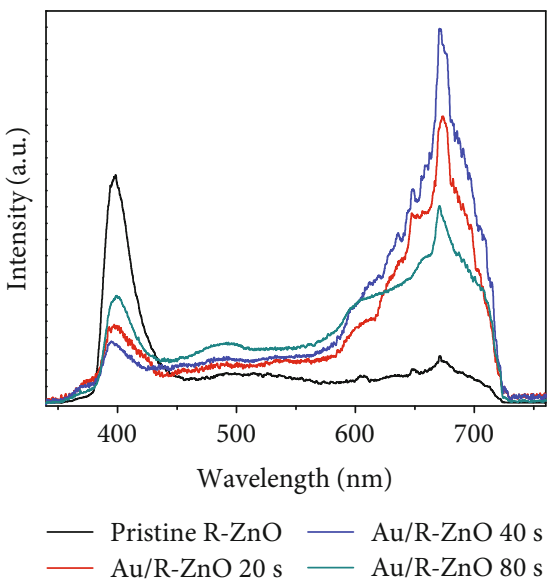

(d)

FIGURE 9: (a)-(d) Steady-state photoluminescence (PL) spectra of Au/ZnO Schottky heterojunction nanocomposites with different deposition times ( $0 \mathrm{~s}, 20 \mathrm{~s}, 40 \mathrm{~s}$, and $80 \mathrm{~s})$ excited by $266 \mathrm{~nm}$, respectively.

peaks located at $493 \mathrm{~nm}(2.52 \mathrm{eV}), 603 \mathrm{~nm}(2.06 \mathrm{eV}), 650 \mathrm{~nm}$ $(1.91 \mathrm{eV})$, and $670 \mathrm{~nm}(1.85 \mathrm{eV})$, which originated from electron transition from single ionized oxygen vacancies $\left(\mathrm{V}_{\mathrm{o}}^{+}\right)$to VB hole radiative recombination [41], band radiative transitions from $\mathrm{Zn}_{\mathrm{i}}$ to $\mathrm{O}_{\mathrm{i}}[42]$, , and photoexcited electron radiative transitions from $\mathrm{CB}$ to doubly ionized oxygen vacancies $\left(\mathrm{V}_{\mathrm{o}}^{++}\right)$defects [43], ,respectively. The steady-state PL spectra of $\mathrm{Au} / \mathrm{E}-\mathrm{ZnO}$ with different $\mathrm{Au} \mathrm{NP}$ loading amounts were plotted in Figure 9(b), which explicitly reveals that a charge transfer was enhanced at the $\mathrm{Au} / \mathrm{E}-\mathrm{ZnO}$ interface when E$\mathrm{ZnO}$ was decorated with Au NPs. Apparently, a decrease in the UV PL-emitted intensity with increasing Au NP depositing time, demonstrating that existence of Au NPs could effectively suppress the direct radiative recombination and facilitated photoformed free electron transport at the $\mathrm{Au} / \mathrm{ZnO}$ interface. Furthermore, visible PL emission intensity (especially for $2.52 \mathrm{eV}$ ) increased with increasing $\mathrm{Au}$ NP loading, which strongly suggests the $\mathrm{V}_{\mathrm{o}}^{+}$defect center was the primary shallow donor energy level in E-ZnO. Similarly, steady-state PL emission spectra were carried out for $\mathrm{Au} / \mathrm{R}-\mathrm{ZnO}$ nanoheterojunctions with different deposition times $(0 \mathrm{~s}, 20 \mathrm{~s}, 40 \mathrm{~s}$, and $80 \mathrm{~s})$, as presented in Figures 9(c) and $9(\mathrm{~d})$, respectively. Figure $9(\mathrm{c})$ illustrated the main fea- tures of steady PL for bare $\mathrm{R}-\mathrm{ZnO}$, which can be deconvoluted into five categories. Two typical PL emission bands were observed: emission at $390 \mathrm{~nm}$ (direct radiative transition from $\mathrm{CB}$ to $\mathrm{VB}$ ) and emission in the visible region (indirect radiative transition from $\mathrm{CB}$ to defect level). Besides the fitting peaks of $390 \mathrm{~nm}, 493 \mathrm{~nm}, 606 \mathrm{~nm}$, and $650 \mathrm{~nm}$, the emission peak located at $670 \mathrm{~nm}$ was inclined to electron radiative transitions from $\mathrm{CB}$ to $\mathrm{V}_{\mathrm{o}}^{++}$defects $[42,43]$. The patterns of steady-state PL spectra for Au/R-ZnO Schottky heterojunctions with different $\mathrm{Au}$ NP loading times were shown in Figure 9(d), disclosing the key role for Au NPs inhibiting the photogenerated $\mathrm{e}^{-}-\mathrm{h}^{+}$pair direct recombination and promoted the charge carriers transfer between the interface of Au NPs and R-ZnO. Moreover, the steady-PL intensities located at $1.85 \mathrm{eV}$ of $\mathrm{Au} / \mathrm{R}-\mathrm{ZnO}$ hybrids distinctly increased with increasing Au NP depositing, indicating that the $\mathrm{V}_{\mathrm{o}}^{++}$defects were the dominant deep donor energy levels in $\mathrm{R}-\mathrm{ZnO}$. Summarizing the above steady-PL analysis, the number of $\mathrm{V}_{\mathrm{o}}^{+}$and $\mathrm{V}_{\mathrm{o}}^{++}$defects was significant increased in $\mathrm{Au} / \mathrm{E}-\mathrm{ZnO}$ and $\mathrm{Au} / \mathrm{R}-\mathrm{ZnO}$ heterojunction nanocomplex with increasing Au NP loading amount, respectively, since the PL emission intensity mainly results from the interband radiative recombination of the photoexcited free charge 
carriers. Hence, we were inclined to believe that a large number of defect active points can be induced at the interface between $\mathrm{Au}$ NPs and $\mathrm{ZnO}$ [44], improving PEC performance was expected.

The essence of the PEC process is photoredox reaction. Elucidation of photoinduced charge transfer dynamic mechanism is vital to understand the subsequent photoredox reactions and also for evaluating the interband electron transition at the interfacial energy band structures of $\mathrm{Au} / \mathrm{ZnO}$ hybrid nanoheterojunctions; time-resolved transient PL spectroscopy characterization technique was evaluated. As we have seen, Figures 10(a)-10(d) presented the NTRT-PL spectra for pristine $\mathrm{E}-\mathrm{ZnO}$ and $\mathrm{Au} / \mathrm{E}-\mathrm{ZnO}$ Schottky nanocomplex with different Au NP depositing times (20s, $40 \mathrm{~s}$, and $80 \mathrm{~s}$ ) in ambient condition at room temperature under $266 \mathrm{~nm}$ fs light irradiation, respectively. In the tested spectral region, the time interval of NTRT-PL was $1.5 \mathrm{~ns}$. Moreover, it is worth mentioning that Yanome et al. [45] had investigated the time scale for electron trapped recombination associated with defect states and holes in VB is a nanosecond order, which determines the photocatalytic activity of the heterojunction nanocomposites. Accordingly, we have reasonably inclined to believe that the NTRT-PL spectrum was in good coincidence with the time scale for free exciton interfacial charge transfer dynamic process.

Meanwhile, Figures 11(a)-11(b) presented schematic illustrations of photoexcited free exciton segregation and reunion transient process for pristine $\mathrm{E}-\mathrm{ZnO}$ and $\mathrm{Au} / \mathrm{E}-$ $\mathrm{ZnO}$ Schottky heterojunctions at room temperature and atmospheric pressure under exciting light of $266 \mathrm{~nm}$ irradiation, respectively. The main photoreaction processes for pristine $\mathrm{E}-\mathrm{ZnO}$, as follows:

$$
\begin{aligned}
& \mathrm{ZnO}+\mathrm{h}_{266 \mathrm{~nm}} \longrightarrow \mathrm{e}_{\mathrm{CB}}^{-}+\mathrm{h}^{+} \mathrm{VB} \\
& \mathrm{e}^{-}{ }_{\mathrm{CB}}+\mathrm{V}_{\mathrm{o}}^{+} \longrightarrow \mathrm{V}_{\mathrm{o}}+\mathrm{h} v_{493 \mathrm{~nm}} \\
& \mathrm{Zn}_{\mathrm{i}}+\mathrm{e}^{-}{ }_{\mathrm{CB}} \longrightarrow \mathrm{O}_{\mathrm{i}}+\mathrm{h} v_{603 \mathrm{~nm}} \\
& \mathrm{e}^{-}{ }_{\mathrm{CB}}+\mathrm{V}_{\mathrm{o}}^{++} \longrightarrow \mathrm{V}_{\mathrm{o}}^{+}+\mathrm{h} v_{650 \mathrm{~nm}} \\
& \mathrm{e}^{-}{ }_{\mathrm{CB}}+\mathrm{V}_{\mathrm{o}}^{++} \longrightarrow \mathrm{V}_{\mathrm{o}}^{+}+\mathrm{h} v_{670 \mathrm{~nm}} \\
& \mathrm{e}^{-}{ }_{\mathrm{CB}}+\mathrm{h}^{+}{ }_{\mathrm{VB}} \longrightarrow \mathrm{h}_{\mathrm{NBE}} \\
& \mathrm{O}_{2}+\mathrm{e}^{-}{ }_{\mathrm{CB}} \longrightarrow \mathrm{O}_{2}{ }^{-} \\
& \mathrm{h}^{+}{ }_{\mathrm{VB}}+\mathrm{OH}^{-} \longrightarrow \cdot \mathrm{OH}
\end{aligned}
$$

Normally, atmospheric molecular oxygen $\left(\mathrm{O}_{2}\right)$ is adsorbed on the surface of $\mathrm{E}-\mathrm{ZnO}$. Initially triggered by $266 \mathrm{~nm}(4.7 \mathrm{eV})$ irradiation $(\mathrm{t}=0 \mathrm{~ns})$, plenty of electrons were promoted from the $\mathrm{VB}$ across the bandgap to the $\mathrm{CB}$ since the energy of excited light is greater than the bandgap value of E-ZnO (equation (1)). Spontaneously, the excitedelectrons of $\mathrm{CB}\left(\mathrm{e}_{\mathrm{CB}}^{-}\right)$were trapped by $\mathrm{V}_{\mathrm{o}}^{+}, \mathrm{Zn}_{\mathrm{i}}$, and $\mathrm{V}_{\mathrm{o}}^{++}$ defects, and emitted transient PL peaks are located at $493 \mathrm{~nm}, 603 \mathrm{~nm}, 650 \mathrm{~nm}$, and $670 \mathrm{~nm}$, respectively (equations (2), (3) (4), (5)). After $1.5 \mathrm{~ns}(t=1.5 \mathrm{~ns})$, the PL peaks located at $390 \mathrm{~nm}$ appeared, which could be ascribed to direct radiative recombination associated with NBE (equation (6)).
The $\mathrm{e}_{\mathrm{CB}}^{-}$increased with increasing spectral recording time $(t=3 \mathrm{~ns})$; apparently, the intensities of transient PL peaks located at $390 \mathrm{~nm}, 493 \mathrm{~nm}, 603 \mathrm{~nm}, 650 \mathrm{~nm}$, and $670 \mathrm{~nm}$ were enhanced compared with that before $1.5 \mathrm{~ns}$. With the evolution of spectral recording time $(t=4.5 \mathrm{~ns})$, a part percentage of $\mathrm{e}_{\mathrm{CB}}^{-}$can be trapped by electron acceptors such as adsorbed $\mathrm{O}_{2}$ on the surface of $\mathrm{E}-\mathrm{ZnO}$ to produce superoxide radical anions $\left(\mathrm{O}_{2}^{-}\right)$(equation (7)), and the holes of $\mathrm{VB}\left(\mathrm{h}^{+}{ }_{\mathrm{VB}}\right)$ could be entrapped by the surface hydroxyl ions $\left(\mathrm{OH}^{-}\right)$to yield hydroxyl radicals $(\cdot \mathrm{OH})$ (equation (8)), which possessed powerful oxidation capability that can degrade the organic molecules. Subsequently, the intensity of transient PL peak located at $390 \mathrm{~nm}$ quenching at the end of recording time ( $t=6 \mathrm{~ns}$ ), which is caused by the immediately decreased concentration of $\mathrm{e}_{\mathrm{CB}}^{-}$.

By contrast, the interfacial charge transfer mechanism for the $\mathrm{Au} / \mathrm{E}-\mathrm{ZnO}$ Schottky nanoheterojunctions as depicted in Figures $10(\mathrm{~b})-10(\mathrm{~d})$ and $11(\mathrm{~b})$. In the initial of spectral recording time $(t=0-1.5 \mathrm{~ns})$, the peak positions of transient $\mathrm{PL}$ spectra were identical with those of pristine $\mathrm{E}-\mathrm{ZnO}$, which originated from $\mathrm{NBE}$ and defect radiative recombination transition. The Schottky barrier height of $\mathrm{Au} / \mathrm{E}-\mathrm{ZnO}$ was determined by the difference between the work function of $\mathrm{Au}$ and the electron affinity for $\mathrm{ZnO}$. Because the work function of $\mathrm{Au}$ is $-5.3 \mathrm{eV}$ [46] (vs. vacuum level) and the electron affinity for $\mathrm{E}-\mathrm{ZnO}$ is approximately $-4.5 \mathrm{eV}$ [47] (vs. vacuum level), so the Schottky barrier should be $0.8 \mathrm{eV}$ [48]. With the lapse of time $(t=3 \mathrm{~ns})$, the intensity of NBE emission band, located at $390 \mathrm{~nm}$, disappeared or had drastic reduction; mainly resulting from the photogenerated $\mathrm{e}_{\mathrm{CB}}^{-}$transfer to $\mathrm{Au}$, driven by a built-in electric field force at the interface between Au NPs and the E-ZnO caused by Schottky barrier (process (1)). At the interface of $\mathrm{Au} / \mathrm{E}-\mathrm{ZnO}$ nanocomplex, the LSPR effect of Au NPs was stimulated by the defect PL emissions of E-ZnO between $500 \mathrm{~nm}$ and $600 \mathrm{~nm}$, which coincided with the UV-vis light absorption characterization. Typically, the free excitons in Au NPs cannot transfer to the $\mathrm{CB}$ of $\mathrm{ZnO}$, in virtue of the obstacle from the Schottky barrier. As the LSPR effect was triggered, plenty of excitons situated at $E_{\mathrm{F}}$ would be excited as "hot electrons" [49] (process (2)). Expectedly, under the recording time evolution ( $t=4.5-6 \mathrm{~ns})$, substantial energetic hot electrons will easily transfer from the Au NPs injected to the CB of E-ZnO (process (3)). This interfacial charge transfer process increased the number of $\mathrm{e}_{\mathrm{CB}}^{-}$and resulted in an enhanced radiative intensity for NBE and defects PL emission, which were characterized by NTRT-PL spectra. Furthermore, it could be definitely observed that the transient PL intensities of defect emissions for samples of $\mathrm{Au} / \mathrm{E}-\mathrm{ZnO} 0 \mathrm{~s}, 80 \mathrm{~s}, 20 \mathrm{~s}$, and $40 \mathrm{~s}$, palpably increased sequentially at recording time of $6 \mathrm{~ns}$, indicating the number of defects associated with photoredox active points induced by Au NPs enhanced in a sequence. During the process of charge transfer, the $\mathrm{O}_{2}$ adsorbed on the surface of $\mathrm{Au}$ NPs, which isattached on $\mathrm{E}-\mathrm{ZnO}$, were able to extract $\mathrm{e}^{-}{ }_{\mathrm{CB}}$ to produce $\cdot \mathrm{O}_{2}{ }^{-}$.

Analogously, to further obtain insightful information for depicting the separation and recombination of photogenerated $\mathrm{e}^{-}-\mathrm{h}^{+}$pairs, from which the efficacy of transportation and entrapping of charge carriers can be obtained. 


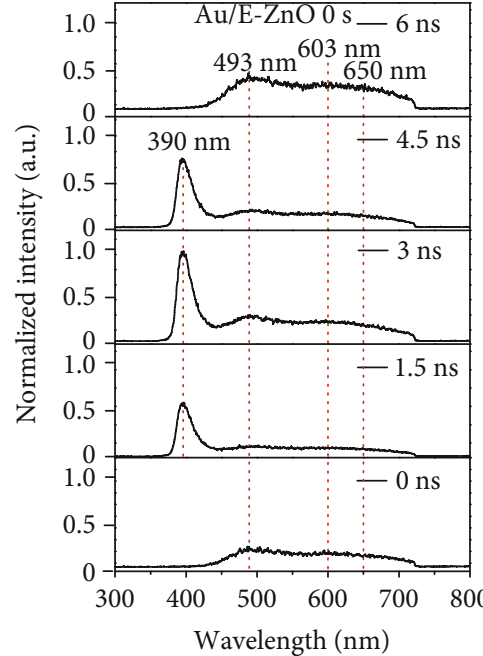

(a)

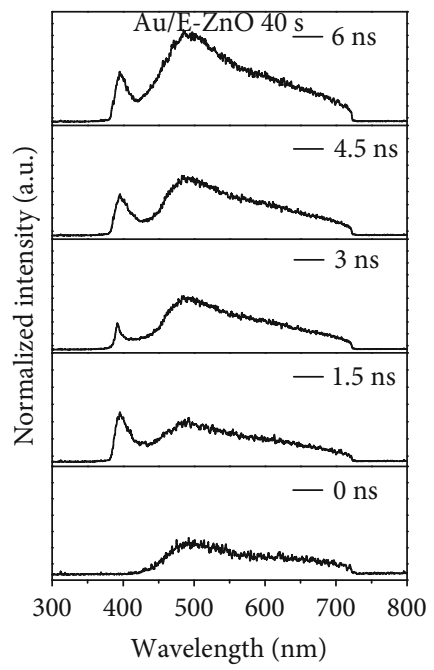

(c)

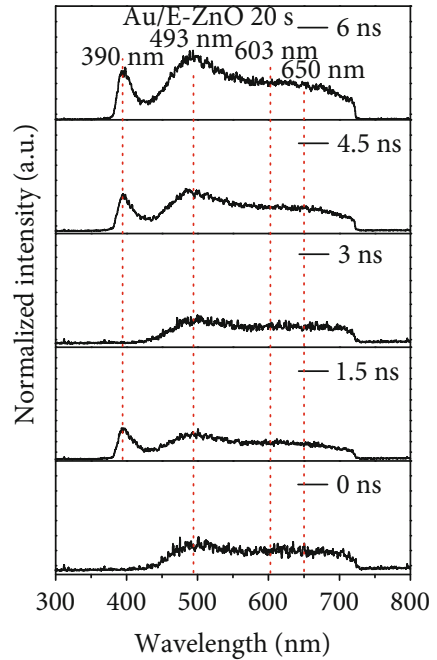

(b)

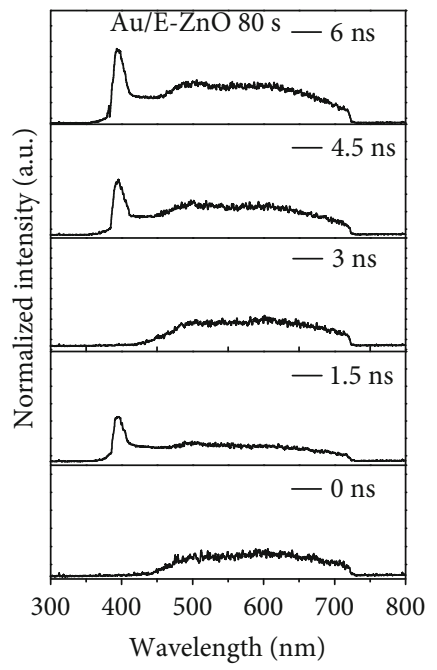

(d)

FIGURE 10: (a)-(d) Normalized nanosecond time-resolved transient photoluminescence (NTRT-PL) spectra of the pristine E-ZnO and Au/E$\mathrm{ZnO}$ Schottky heterojunction nanocomposites for different deposition times (20 s, $40 \mathrm{~s}$, and $80 \mathrm{~s})$, respectively.

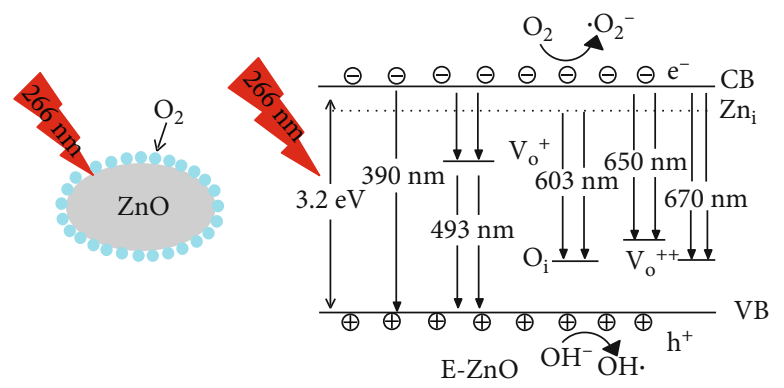

(a)

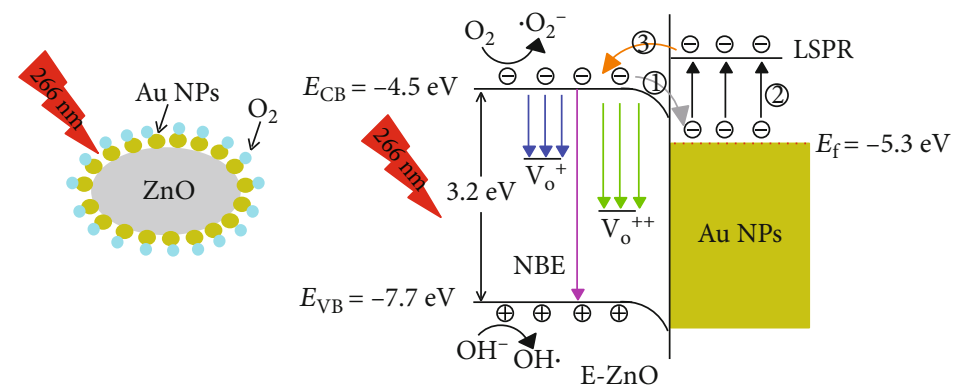

(b)

FIGURE 11: Schematic illustrations of photogenerated carrier transfer and recombination transient process for pristine E-ZnO (a) and Au/E$\mathrm{ZnO}$ nanosystem (b) in ambient condition under $266 \mathrm{~nm}$ irradiation, respectively.

Figures 12(a)-12(d) and 13(a) and 13(b) exhibited the NTRT-PL spectra and graphic illustrations of the transient $\mathrm{PL}$ process for $\mathrm{Au} / \mathrm{R}-\mathrm{ZnO}$ Schottky nanocomposites with different deposition times $(0 \mathrm{~s}, 20 \mathrm{~s}, 40 \mathrm{~s}$, and $80 \mathrm{~s})$ in room temperature atmospheric environment under $266 \mathrm{~nm}$ irradiation, respectively. We referred to photoreaction equations 


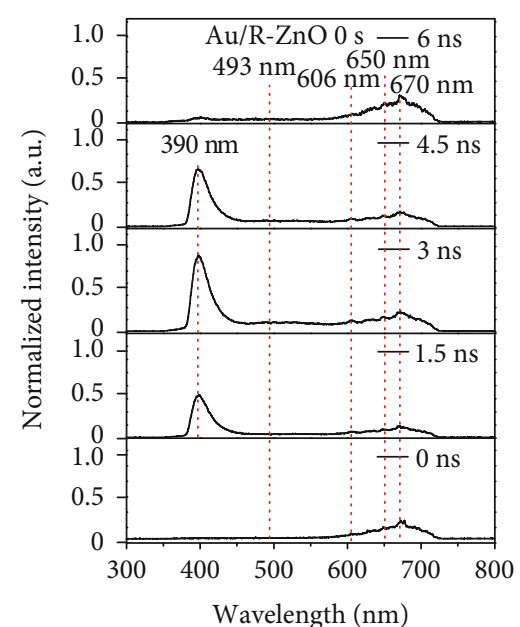

(a)

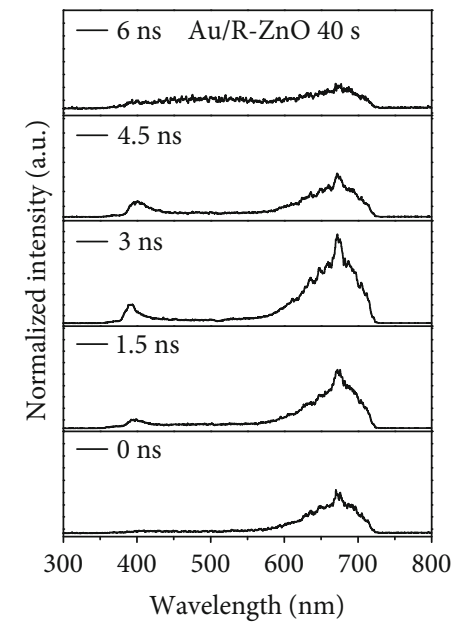

(c)

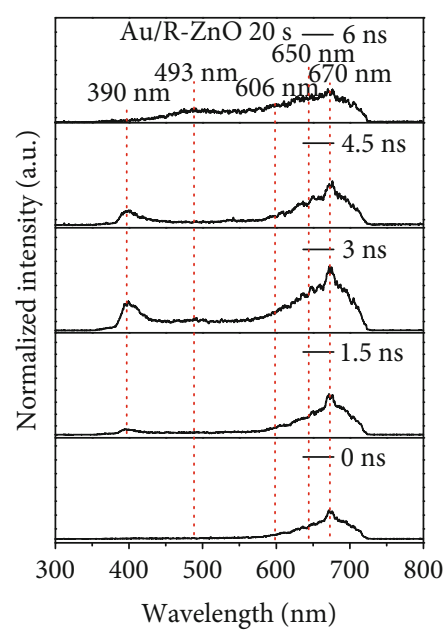

(b)

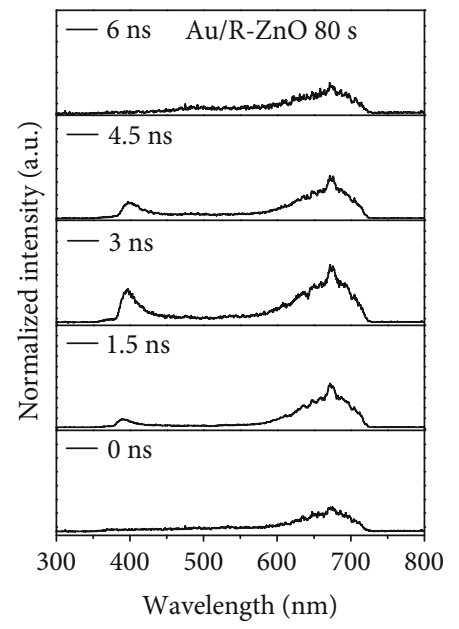

(d)

Figure 12: (a)-(d) The normalized NTRT-PL spectra of pristine R-ZnO, and Au/R-ZnO Schottky heterojunction nanocomposites for different deposition times (20s, 40s, and 80s), respectively.

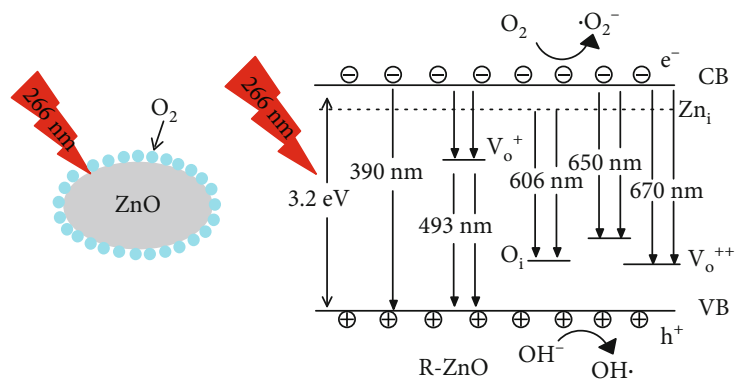

(a)

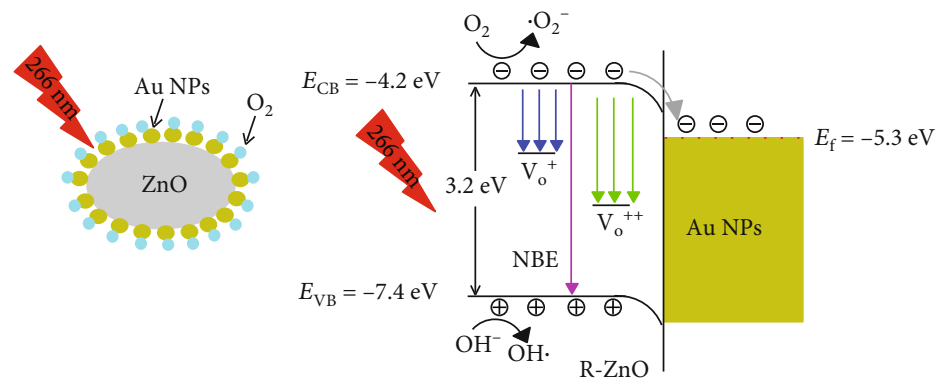

(b)

FIGURE 13: Schematic illustrations of photogenerated carrier transfer and recombination transient process for pristine R-ZnO (a) and Au/R$\mathrm{ZnO}$ nanosystem (b) in ambient condition under $266 \mathrm{~nm}$ irradiation, respectively.

for bare $\mathrm{R}-\mathrm{ZnO}$, including production, capture, and consumption of photoexcited electrons, as follows:

$$
\begin{array}{r}
\mathrm{ZnO}+\mathrm{h}_{266 \mathrm{~nm}} \longrightarrow \mathrm{e}_{\mathrm{CB}}^{-}+\mathrm{h}_{\mathrm{VB}}^{+} \\
\mathrm{e}^{-}{ }_{\mathrm{CB}}+\mathrm{V}_{\mathrm{o}}^{+} \longrightarrow \mathrm{V}_{\mathrm{o}}+\mathrm{h} v_{493 \mathrm{~nm}}
\end{array}
$$

$$
\begin{gathered}
\mathrm{e}_{\mathrm{CB}}^{-}+\mathrm{V}_{\mathrm{o}}^{++} \longrightarrow \mathrm{V}_{\mathrm{o}}^{+}+\mathrm{h} v_{650 \mathrm{~nm}} \\
\mathrm{e}_{\mathrm{CB}}^{-}+\mathrm{h}_{\mathrm{VB}}^{+} \longrightarrow \mathrm{h} v_{\mathrm{NBE}} \\
\mathrm{O}_{2}+\mathrm{e}_{\mathrm{CB}}^{-} \longrightarrow \cdot \mathrm{O}_{2}^{-}
\end{gathered}
$$




$$
\begin{aligned}
\mathrm{h}^{+}{ }_{\mathrm{VB}}+\mathrm{OH}^{-} & \longrightarrow \cdot \mathrm{OH} \\
\mathrm{Zn}_{\mathrm{i}}+\mathrm{e}^{-}{ }_{\mathrm{CB}} & \longrightarrow \mathrm{O}_{\mathrm{i}}+\mathrm{h} v_{606 \mathrm{~nm}} \\
\mathrm{e}^{-}{ }_{\mathrm{CB}}+\mathrm{V}_{\mathrm{o}}^{++} & \longrightarrow \mathrm{V}_{\mathrm{o}}^{+}+\mathrm{h} v_{670 \mathrm{~nm}}
\end{aligned}
$$

At the beginning of the photoexcitation through $266 \mathrm{~nm}$ fs light irradiation ( $t=0 \mathrm{~ns})$, it is well known that the photogenerated electrons were directly stimulated from the VB to the $\mathrm{CB}$ since the energy of incident photons was larger than the threshold energy of $\mathrm{R}-\mathrm{ZnO}$ (equation (1)). Subsequently, the transient PL peaks located at $493 \mathrm{~nm}$, $606 \mathrm{~nm}, 650 \mathrm{~nm}$, and $670 \mathrm{~nm}$ appeared, which are ascribed to radiative recombination associated with $\mathrm{V}_{\mathrm{o}}^{+}, \mathrm{O}_{\mathrm{i}}$, and $\mathrm{V}_{\mathrm{o}}^{++}$intrinsic point defects, respectively (equations (2), (4), (8), and (16)). As recording time goes after $1.5 \mathrm{~ns}(t=1.5$ ns), the NBE emission transient PL peak located at $390 \mathrm{~nm}$ emerged, attributing to $\mathrm{e}_{\mathrm{CB}}^{-}$and $\mathrm{h}^{+}{ }_{\mathrm{VB}}$ in $\mathrm{ZnO}$ direct radiative recombination (equation (5)). While concentration of $\mathrm{e}^{-}{ }_{C B}$ increased with increasing the recording time $(t=3 \mathrm{~ns})$, the NBE emission PL intensity was remarkably enhanced, meanwhile the transient PL intensities of defects were significantly improved. Under the recording time evolution $(t=4.5 \mathrm{~ns})$, all the transient PL intensities evidently depressed, compared with that at previous recording time. We have a reason to believe the results arised from $\mathrm{e}_{\mathrm{CB}}^{-}$ extracted by adsorbed $\mathrm{O}_{2}$ on the surface of $\mathrm{R}-\mathrm{ZnO}$ to produce. $\mathrm{O}_{2}^{-}$(equation (6)), accompanied by $\mathrm{h}^{+}{ }_{\mathrm{VB}}$ combined with $\mathrm{OH}^{-}$to generate $\cdot \mathrm{OH}$ (equation (7)). The sustained consumption of $\mathrm{e}^{-}{ }_{C B}$ with the evolution of spectral recording time $(t=6 \mathrm{~ns})$, giving rise to the quenched transient PL intensity of $390 \mathrm{~nm}$ and depressed defects PL emission.

Figures 12(b)-12(d) and 13(b) demonstrated transient PL spectra and credible mechanism explanation for $\mathrm{Au} / \mathrm{R}-\mathrm{ZnO}$ nanoheterojunctions, respectively. In the present case, considering the difference of electron affinity and work function for R-ZnO and Au NPs (-4.2 eV and $-5.3 \mathrm{eV}$ vs. vacuum level, respectively) was $1.1 \mathrm{eV}$ [50], which formed the Schottky barrier is slightly higher than that of E-ZnO. Accordingly, the initial electrons transfer between the $\mathrm{R}-\mathrm{ZnO}$ and $\mathrm{Au}$ NPs would cause a band bending. Irradiation of the $\mathrm{Au} / \mathrm{R}-\mathrm{ZnO}$ nanocomposites by $266 \mathrm{~nm}$ exciting light at initial time $(t=0-1.5 \mathrm{~ns})$ would excite the free electrons in $\mathrm{VB}$ to the CB, which is higher than the $\mathrm{CB}$ edge of $\mathrm{R}-\mathrm{ZnO}$. The highdensity $\mathrm{e}_{\mathrm{CB}}^{-}$can be transferred to the defect levels of $\mathrm{ZnO}$ if they are situated below the Fermi level $\left(\mathrm{E}_{\mathrm{F}}\right)$ of $\mathrm{Au}$, causing an enhancement of defect emission. Remarkably, Gong et al. [51] emphasized that the dominant $V_{0}$ defect states in $\mathrm{R}$ $\mathrm{ZnO}$ are $\mathrm{V}_{\mathrm{o}}^{++}$defects, which ascribed to $\mathrm{V}_{\mathrm{o}}^{+}$defects would be formed to higher total energy than $\mathrm{V}_{\mathrm{o}}^{++}$defects. Thus, the defect PL emission heavily focused on $650 \mathrm{~nm}$ and $670 \mathrm{~nm}$, which originated from $\mathrm{e}_{\mathrm{CB}}^{-}$radiative trapped by $\mathrm{V}_{\mathrm{o}}^{++}$defects. The concentration of $\mathrm{e}^{-}{ }_{\mathrm{CB}}$ increased with increasing recording time $(t=3 \mathrm{~ns})$; a great many of $\mathrm{e}^{-}$ direct recombination with the $\mathrm{h}_{\mathrm{VB}}{ }^{+}$to radiate higher $390 \mathrm{~nm}$ emission light, besides, transient PL intensity of defect emission turned more stronger. As we known, $\mathrm{O}_{2}$ can be much efficiently adsorbed on the surface of Au NPs, which acted as the electron acceptor via a built-in electric field force at the interface of $\mathrm{Au} / \mathrm{R}-\mathrm{ZnO}$ Schottky nanohybrids. Au NPs served as "transit depot" of electrons in the whole transient charge transfer process. Subsequently, at the last stage of the transient PL recording time $(t=4.5-6 \mathrm{~ns})$, owing to the substantial interfacial tranfer of $\mathrm{e}_{\mathrm{CB}}$ - from $\mathrm{R}-\mathrm{ZnO}$ to $\mathrm{Au} \mathrm{NPs}$ associated with powerful Schottky barrier, the PL intensity of NBE and $\mathrm{V}_{\mathrm{o}}{ }^{++}$defect emission decreased gradually until it vanished with the evolution of recording time. Evidently, LSPR effect cannot be excited by Au/R-ZnO Schottkyheterojunction nanocomplex, possibly originating from its defect PL irradiation around $650 \mathrm{~nm}-670 \mathrm{~nm}$, which deviated from the excitation range for Au NP LSPR effect. It is worth mentioning that the difference of interfacial charge transfer from $\mathrm{ZnO}$ to $\mathrm{Au} \mathrm{NPs}$ for $\mathrm{Au} / \mathrm{E}-\mathrm{ZnO}$ and $\mathrm{Au} / \mathrm{R}-\mathrm{ZnO}$, mainly attributing to the specific surface area of $\mathrm{E}-\mathrm{ZnO}$ is larger than that of $\mathrm{R}-\mathrm{ZnO}$, which favored more adsorption of $\mathrm{O}_{2}$ and witness by previous SEM characterization.

Time-resolved PL (TRPL) decay spectrum is a powerful and nondestructive detection technique, which is typically used to probe the $\mathrm{e}_{\text {Св }}^{-}$lifetime of the specific emission band. To further obtain insightful information for elucidating the charge transfer (i.e., charge injection) efficiency and evaluating the carrier lifetime at the interface between $\mathrm{Au} \mathrm{NPs}$ and $\mathrm{ZnO}$ Schottky-heterojunctions, TRPL decay profiles were performed for the samples of $\mathrm{Au} / \mathrm{R}-\mathrm{ZnO} 20 \mathrm{~s}$ and $\mathrm{Au} / \mathrm{E}-\mathrm{ZnO} 0 \mathrm{~s}$, $20 \mathrm{~s}, 40 \mathrm{~s}$, and $80 \mathrm{~s}$ with the excitation wavelength of $350 \mathrm{~nm}$ at room temperature for NBE emission band, respectively, as illustrated as Figure 14. Currently, the TRPL decay curves were well fitted to the biexponential pattern described by the equation: $I(t)=A_{1} \exp \left(-t / \tau_{1}\right)+A_{2} \exp \left(-t / \tau_{2}\right)$, and the $\mathrm{e}_{\mathrm{CB}}^{-}$ average lifetime ( $\left.\tau_{\text {avg }}\right)$ of the samples were calculated from the relation: $\tau_{\text {avg }}=\left(A_{1} \tau_{1}{ }^{2}+A_{2} \tau_{2}{ }^{2}\right) /\left(A_{1} \tau_{1}+A_{2} \tau_{2}\right)$, where $\tau_{1}$ is the fast decay component related to the free excitons and $\tau_{2}$ represents the slow decay component associated with the bound excitons. $A_{1}, A_{2}$ are the relative amplitude of fast decay and slow decay, respectively. Simultaneously, the efficiency of hot carrier injection $\left(\eta_{\text {in }}\right)$, which originated from the LSPR effect excited by Au NPs, can be obtained from the defined relation: $\eta_{\text {in }}=\left[\tau_{\text {avg }(\mathrm{Au} / \mathrm{E}-\mathrm{ZnO})}-\tau_{\mathrm{avg}(\mathrm{E}-\mathrm{ZnO})}\right] / \tau_{\mathrm{avg}(\mathrm{E}-\mathrm{ZnO})}$, where $\tau_{\text {avg }(\mathrm{Au} / \mathrm{E}-\mathrm{ZnO})}$ represents the average lifetime for $\mathrm{Au} / \mathrm{E}-\mathrm{ZnO}$ nanohybrid and $\tau_{\text {avg }(\mathrm{E}-\mathrm{ZnO})}$ is the average lifetime for pristine E-ZnO. Table 2 presents the values of $A_{1}, A_{2}$, and $\tau_{\text {avg }}$ of $\mathrm{e}_{\mathrm{CB}}^{-}$, and $\eta_{\text {in }}$ for $\mathrm{Au} / \mathrm{R}-\mathrm{ZnO} 20 \mathrm{~s}$ and $\mathrm{Au} / \mathrm{E}-\mathrm{ZnO}$ Schottkyheterojunctions with different Au NP amount $(0$ s, 20 s, 40 s, and 80 s), respectively.

As illustrated in Table 2, the $\tau_{\text {avg }}$ for $\mathrm{Au} / \mathrm{R}-\mathrm{ZnO} 20$ s, pristine $\mathrm{E}-\mathrm{ZnO}$, and $\mathrm{Au} / \mathrm{E}-\mathrm{ZnO}$ with different $\mathrm{Au} \mathrm{NP}$ depositing times for $20 \mathrm{~s}, 40 \mathrm{~s}$, and $80 \mathrm{~s}$ are $4.04 \mathrm{~ns}, 5.15 \mathrm{~ns}, 6.46 \mathrm{~ns}$, $7.31 \mathrm{~ns}$, and $5.68 \mathrm{~ns}$, respectively. It can be distinctly discovered that the $\tau_{\text {avg }}$ of $\mathrm{e}_{\mathrm{CB}}^{-}$for $\mathrm{Au} / \mathrm{R}-\mathrm{ZnO} 20 \mathrm{~s}$ is minimum, and the $\tau_{\text {avg }}$ and $\eta_{\text {in }}$ increased with the Au NP depositing time increasing from $20 \mathrm{~s}$ to $40 \mathrm{~s}$ and then decreased with a continuous distribution of Au NP deposition time $80 \mathrm{~s}$ was applied. Logically, the $\tau_{\text {avg }}$ of the photogenerated carrier is heavily depended on the concentration of $\mathrm{e}_{\mathrm{CB}}^{-}$. The NBE emission band located at $390 \mathrm{~nm}$ resulted from the direct radiative recombination of $\mathrm{ZnO}$ between $\mathrm{CB}$ and $\mathrm{VB}$. Therefore, the raise of $\tau_{\text {avg }}$ for $\mathrm{Au} / \mathrm{E}-\mathrm{ZnO}$ samples compared with 


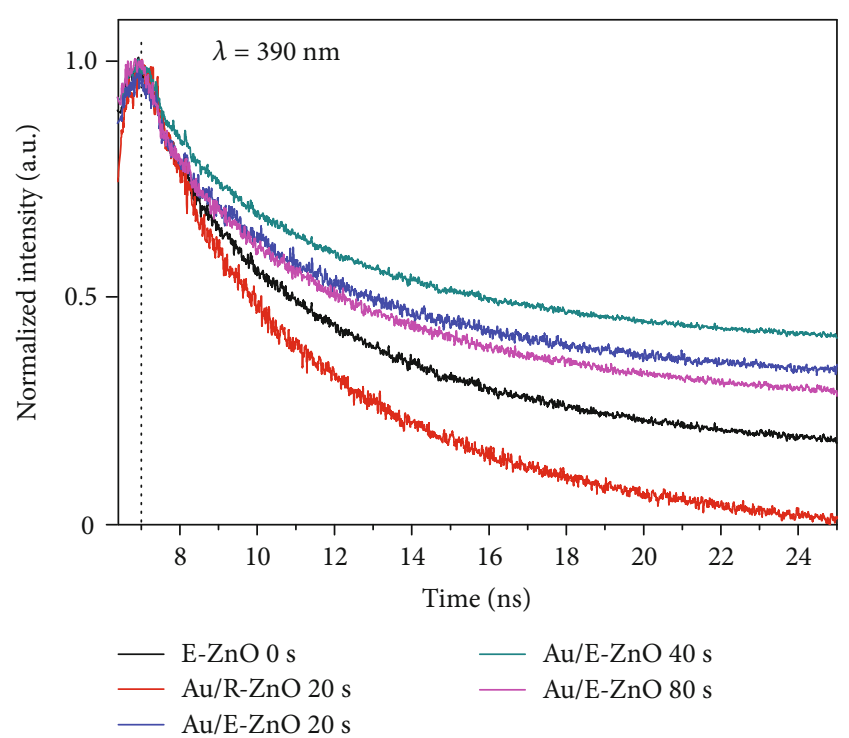

FIGURE 14: Normalized time-resolved PL decay spectra of the Au/R$\mathrm{ZnO} 20 \mathrm{~s}$ and $\mathrm{Au} / \mathrm{E}-\mathrm{ZnO}$ Schottky-heterojunction nanocomplex for Au NPs with different deposition times: 0 s, 20 s, 40 s, and 80 s, at the wavelength of $390 \mathrm{~nm}$, respectively.

TABle 2: Fast and slow decay times along with their amplitudes, average lifetime $\left(\tau_{\text {avg }}\right)$, and carrier injection efficiency $\left(\eta_{\text {in }}\right)$ for $\mathrm{Au} / \mathrm{R}-\mathrm{ZnO}$ and $\mathrm{Au} / \mathrm{E}-\mathrm{ZnO}$ Schottky-heterojunction nanocomplex with different Au NP deposition times, respectively.

\begin{tabular}{lcccccc}
\hline Sample codes & $\begin{array}{c}\tau_{1} \\
(\mathrm{~ns})\end{array}$ & $\begin{array}{c}A_{1} \\
(\%)\end{array}$ & $\begin{array}{c}\tau_{2} \\
(\mathrm{~ns})\end{array}$ & $\begin{array}{c}A_{2} \\
(\%)\end{array}$ & $\begin{array}{c}\tau_{\text {avg }} \\
(\mathrm{ns})\end{array}$ & $\eta_{\text {in }}(\%)$ \\
\hline $\begin{array}{l}\mathrm{Au} / \mathrm{R}-\mathrm{ZnO} \\
20 \mathrm{~s}\end{array}$ & 2.06 & 70.6 & 5.74 & 29.4 & 4.04 & - \\
$\begin{array}{l}\mathrm{Au} / \mathrm{E}-\mathrm{ZnO} 0 \mathrm{~s} \\
\mathrm{Au} / \mathrm{E}-\mathrm{ZnO}\end{array}$ & 3.24 & 73.3 & 7.35 & 26.7 & 5.15 & - \\
$20 \mathrm{~s}$ & 3.71 & 64.8 & 8.66 & 35.2 & 6.46 & 25.43 \\
$\begin{array}{l}\mathrm{Au} / \mathrm{E}-\mathrm{ZnO} \\
40 \mathrm{~s}\end{array}$ & 3.92 & 58.9 & 9.33 & 41.1 & 7.31 & 41.95 \\
$\begin{array}{l}\mathrm{Au} / \mathrm{E}-\mathrm{ZnO} \\
80 \mathrm{~s}\end{array}$ & 3.42 & 68.5 & 7.82 & 31.5 & 5.68 & 10.29 \\
\hline
\end{tabular}

pristine $\mathrm{E}-\mathrm{ZnO}$, resulting from the $\mathrm{e}_{\mathrm{CB}}^{-}$injection excited by Au NPs; yet, the depression of $\tau_{\text {avg }}$ for $\mathrm{Au} / \mathrm{R}-\mathrm{ZnO} 20 \mathrm{~s}$ sample associated with the reduction of $\mathrm{e}_{\mathrm{CB}}^{-}$concentration, which were attributed to intenser built-in electric field force induced by Schottky barrier and higher charge transfer efficiency [52]. The parameter $\eta_{\text {in }}$ with a direct correlation to the amount of hot electron injection, which is sensitive with the discrete particle size of Au NPs. The increased particle size with the increasing Au NP deposition time from $20 \mathrm{~s}$ to $40 \mathrm{~s}$ coincides with promoting intension of hot electron cyclic injection. As the $\mathrm{Au}$ NP depositing time was 80 s, the surface of $\mathrm{E}-\mathrm{ZnO}$ is covered with successive films constructed by Au NPs, which presumaed strong decoupling the resonance effect between $\mathrm{E}-\mathrm{ZnO}$ and $\mathrm{Au}$ NPs.

In the $\mathrm{Au} / \mathrm{E}-\mathrm{ZnO}$ Schottky nanocomposites, the Au NPs can be regarded as a circular bridge of carrier transport, which transfer the $\mathrm{V}_{\mathrm{o}}^{+}$defects PL emission energy to the
NBE emission, and resulted in the prolonged $\tau_{\text {avg }}$ of photoexcited charge carriers. Meanwhile, the longer $\tau_{\text {avg }}$ is associated with more effective separation of $\mathrm{e}^{-}-\mathrm{h}^{+}$pairs, which demonstrates more photogenerated charges would participate in PEC reactions. By contrast, the Au NPs really act as transit depot of unidirectional $\mathrm{e}_{\mathrm{CB}}^{-}$transfer in the $\mathrm{Au} / \mathrm{R}-\mathrm{ZnO}$ Schottky nanocomplex, which relied on vigorous internal electronic driving force in the charge depletion region and acquired effective transfer capability for interfacial photoinduced carriers. There is an obvious contradiction between impressive injection of energetic electrons and rapid interfacial electroic transport for more effectively boost the PEC activity.

In order to validate the hypothesis, we carried out the experiments of MO photodegradation for the samples of $\mathrm{Au} / \mathrm{R}-\mathrm{ZnO} 20 \mathrm{~s}$ and $\mathrm{Au} / \mathrm{E}-\mathrm{ZnO}$ with different $\mathrm{Au} \mathrm{NP}$ content under UV light irradiation, respectively. The excitation wavelength of UV irradiated was $254 \mathrm{~nm}$ with luminescence power $11 \mathrm{~W}$, which is in accordance with the excited wavelength of $266 \mathrm{~nm}$ for the steady- and transient-state PL investigation. Detailed photodegradation experimental procedures were described above, using concentration of $\mathrm{MO}(10 \mathrm{mg} / \mathrm{L})$ in the photocatalytic experiment. The photodegradation efficiency $(\eta)$ of MO could be calculated as $\eta(\%)=\left[\left(C_{0}-C\right) /\right.$ $\left.C_{0}\right] \times 100 \%$, where $C_{0}$ is the initial concentration of the MO, and $C$ is the concentration after photoirradiation. Figure 15 presents the experimental results of five cycles under the same conditions under UV irradiation, respectively. The average $\eta$ for self-degradation efficiency of $\mathrm{MO}, \mathrm{Au} / \mathrm{R}-\mathrm{ZnO} 20 \mathrm{~s}$, and the $\mathrm{Au} / \mathrm{E}-\mathrm{ZnO}$ Schottky nanocomposites with different $\mathrm{Au}$ $\mathrm{NP}$ depositing times $(0 \mathrm{~s}, 20 \mathrm{~s}, 40 \mathrm{~s}$, and $80 \mathrm{~s})$ are equal to $10.6 \%, 51.3 \%, 25.2 \%, 64.1 \%, 72.8 \%$, and $55.6 \%$, respectively. This results distinctly indicate that Au NPs play a vital role in facilitating a photoexcited electron transfer to the interface before it is radiatively recombined at defects or band edge emission. Meanwhile, the UV photocatalytic activities increased with the Au NP-decorated E-ZnO film depositing time increased from $0 \mathrm{~s}$ to $40 \mathrm{~s}$ and then decreased with deposition time $80 \mathrm{~s}$, which coincided with the ultrafast dynamics of charge injection between E-ZnO and Au NPs.

In order to evaluate the reaction kinetics of the MO photodegradation catalyzed by $\mathrm{Au} / \mathrm{R}-\mathrm{ZnO} 20$ s, pristine E$\mathrm{ZnO}$, and $\mathrm{Au} / \mathrm{E}-\mathrm{ZnO}$ with $\mathrm{Au} \mathrm{NP}$ deposition times $20 \mathrm{~s}$, $40 \mathrm{~s}$, and $80 \mathrm{~s}$, the experimental data in Figure 16 were fitted by the Langmuir-Hinshelwood equation: $\ln \left(C_{0} / C\right)=k t$, where $C_{0}$ and $C$ are the initial and residual concentration of $\mathrm{MO}$ in reaction mixture $(\mathrm{mg} / \mathrm{L}), t$ refers to exposure time (hour), and $k$ is the reaction rate constant. According to the approximate linear fitting curves of $\ln \left(C_{0} / C\right)$ versus irradiation time $t$, the values of $k$ for above samples were calculated to be $0.00042 \mathrm{~min}^{-1}, 0.0063 \mathrm{~min}^{-1}, 0.002 \mathrm{~min}^{-1}, 0.0067 \mathrm{~min}^{-1}$, $0.0073 \mathrm{~min}^{-1}$, and $0.0081 \mathrm{~min}^{-1}$, respectively. It is explicitly demonstrated that $k$ of $\mathrm{ZnO}$ decorated with Au NPs were significantly higher than that of bare $\mathrm{ZnO}$, benefiting from the synergetic effect of energetic charge injection and expeditious interfacial charge transfer. Furtermore, Au NPs also absorb the UV light to cause electron transition from $5 \mathrm{~d}$ to $6 \mathrm{sp}$ band, which leads to the improved PEC performance of $\mathrm{Au} / \mathrm{ZnO}$ in comparison with pristine $\mathrm{ZnO}$. In addition, the magnitude of the reaction rate is strong depending on the 


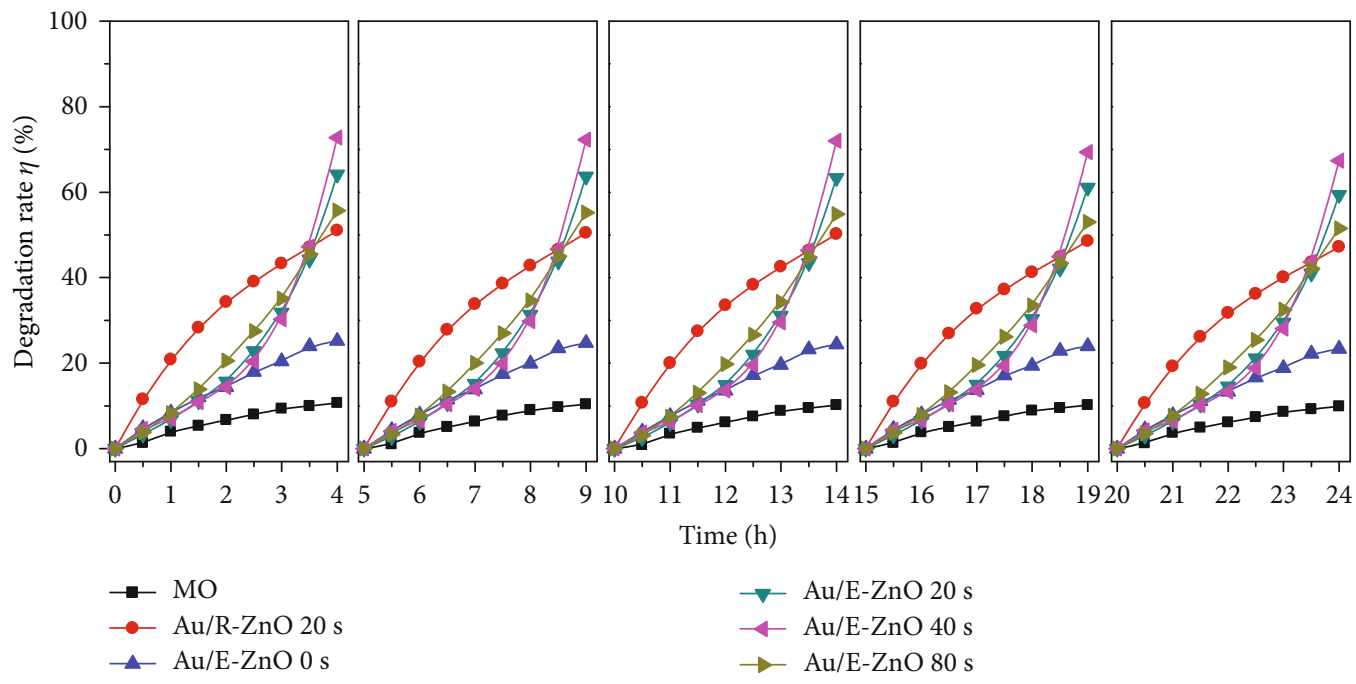

Figure 15: Cyclic photodegradation efficiency of methyl orange (MO), the Au/R-ZnO 20 s, and Au/E-ZnO Schottky heterojunctions with different deposition times $(0 \mathrm{~s}, 20 \mathrm{~s}, 40 \mathrm{~s}$, and $80 \mathrm{~s})$ irradiated with UV lamp under the same condition five times, respectively.

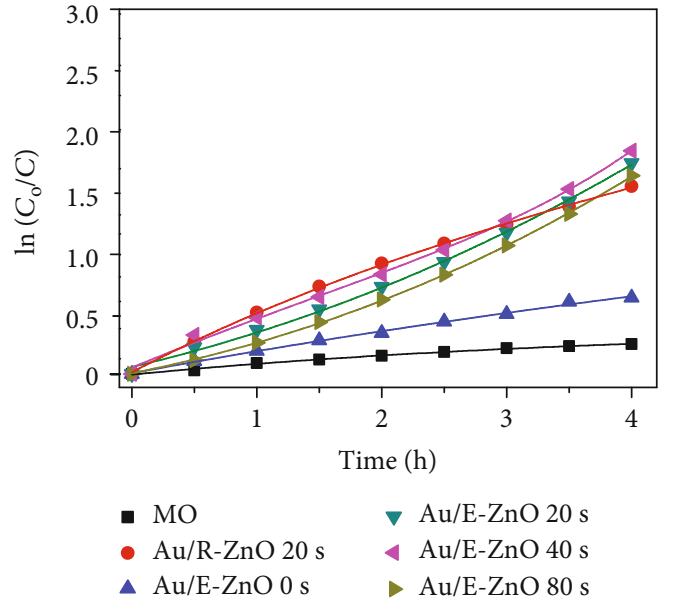

Figure 16: Plot of $\ln \left(C_{0} / C\right)$ versus irradiation time of $\mathrm{MO}$ degradation, $\mathrm{Au} / \mathrm{R}-\mathrm{ZnO} 20$ s, pristine $\mathrm{Au} / \mathrm{E}-\mathrm{ZnO}$, and $\mathrm{Au} / \mathrm{E}-\mathrm{ZnO}$ nanocomplex with different $\mathrm{Au}$ content $(20 \mathrm{~s}, 40 \mathrm{~s}$, and $80 \mathrm{~s}$ ) irradiated with UV light, respectively.

amount of defect sites, which is associated with the aspect ratio of the specimen. Besides the strong electronic interaction between $\mathrm{Au}$ NPs and $\mathrm{ZnO}$ can be induced by the LSPR effect, a higher specific surface area is another vital factor improving photocatalytic activity, which resulted in a remarkable promotion in photodegradation rate of $\mathrm{Au} / \mathrm{E}-$ $\mathrm{ZnO}$ compared with $\mathrm{Au} / \mathrm{R}-\mathrm{ZnO}$. The $k$ of $\mathrm{Au} / \mathrm{E}-\mathrm{ZnO}$ heterojunctions increased from $0 \mathrm{~s}$ to $40 \mathrm{~s}$ and then decreased with deposition time 80 s, originating from injection efficiency of hot electrons induced by more appropriate particle size of Au NPs, which is in accordance with our expectation.

\section{Conclusion}

In summary, $\mathrm{Au} / \mathrm{R}-\mathrm{ZnO}$ and $\mathrm{Au} / \mathrm{E}-\mathrm{ZnO}$ Schottky heterojunction nanocomposites were successfully synthesised through a two-step electrochemical and ion-sputtering depo- sition method, and they exhibited fascinated interfacial charge transfer process mediated by $\mathrm{V}_{\mathrm{o}}$ defects under $266 \mathrm{~nm}$ irradiation, which is witnessed by NTRT-PL spectra and XPS analysis. Furthermore, the surface decoration of plasmonic Au NPs has been demonstrated as an effective approach to improve the PEC performance irradiated by UV light, ascribing to the synergistic effects of energenic electrons injection and rapid interfacial charge transfer. For $\mathrm{Au} / \mathrm{E}-\mathrm{ZnO}$ nanocomplex, the injection electron process from plasmonic Au NPs into the E-ZnO matrix is the key factor for enhancing the efficiency of the photocatalytic degradation process. Yet for $\mathrm{Au} / \mathrm{R}-\mathrm{ZnO}$ nanocomposites, the attached $\mathrm{Au}$ NPs at the surface of R-ZnO form close Schottky barrier contacts between the metal and semiconductor play a crucial role for improving the PEC activity during UV light irradiation. In addition, the difference roles of $\mathrm{Au} N \mathrm{NP}$ in $\mathrm{Au} / \mathrm{ZnO}$ Schottky nanoheterojuntions are discussed separately, associated with transient PL emission of NBE as well as defects, which acts as "annular-bridge" and "transit depot" in $\mathrm{Au} / \mathrm{E}-\mathrm{ZnO}$ and $\mathrm{Au} / \mathrm{R}-\mathrm{ZnO}$ nanohybrids, respectively. This proposals are supported by the characterisations of steadyand transient-state PL spectra, which explicitly reveal the intrinsic competition relations between the interfacial transfer of photogenerated $\mathrm{e}^{-}-\mathrm{h}^{+}$pairs and recombination process. We believe that the design and synthesized $\mathrm{Au} / \mathrm{ZnO}$ nanostructure in this work not only provides new insights into the mechanism of interfacial charge transfer assoiated with $\mathrm{V}_{\mathrm{o}}$ defects but also exploits new prospects for the development of M/S Schottky heterojunction-improved PEC devices.

\section{Data Availability}

All data, models, and code generated or used during the study appear in the submitted article.

\section{Conflicts of Interest}

There are no conflicts of interest to declare. 


\section{Acknowledgments}

We are thankful to the financial support of the National Natural Science Foundation of China (NSFC) (Grant No. 61474009 and Grant No. 61575029) and LiaoNing Revitalization Talents Program (XLYC1907173).

\section{References}

[1] Y. Lee, S. Kim, S. Y. Jeong et al., "Surface-modified co-doped $\mathrm{ZnO}$ photoanode for photoelectrochemical oxidation of glycerol," Catalysis Today, 2019.

[2] X. Zheng, Y. Sun, H. Qin, and Z. Ji, "Solar-charged pseudocapacitors: simultaneous conversion and storage of solar energy in ZnO@NiO nanorod arrays," Journal of Alloys and Compounds, vol. 781, pp. 351-356, 2019.

[3] Q. Liang, F. Qiao, X. Cui, and X. Hou, "Controlling the morphology of $\mathrm{ZnO}$ structures via low temperature hydrothermal method and their optoelectronic application," Materials Science in Semiconductor Processing, vol. 89, pp. 154-160, 2019.

[4] B. Pant, G. P. Ojha, H. Y. Kim, M. Park, and S. J. Park, "Flyash-incorporated electrospun zinc oxide nanofibers: potential material for environmental remediation," Environmental Pollution, vol. 245, pp. 163-172, 2019.

[5] H. Y. Phin, Y. T. Ong, and J. C. Sin, "Effect of carbon nanotubes loading on the photocatalytic activity of zinc oxide/carbon nanotubes photocatalyst synthesized via a modified solgel method," Journal of Environmental Chemical Engineering, vol. 8, no. 3, article 103222, 2020.

[6] T. Saito, R. Iba, S. Ono, G. Imada, and K. Yasui, "Growth characteristics of $\mathrm{ZnO}$ thin films produced via catalytic reaction-assisted chemical vapor deposition," Journal of Vacuum Science \& Technology A, vol. 37, no. 3, article 030904, 2019.

[7] N. N. Huy, V. T. Thanh Thuy, N. H. Thang et al., "Facile onestep synthesis of zinc oxide nanoparticles by ultrasonicassisted precipitation method and its application for $\mathrm{H}_{2} \mathrm{~S}$ adsorption in air," Journal of Physics and Chemistry of Solids, vol. 132, pp. 99-103, 2019.

[8] F. Meng, F. Ge, Y. Chen, G. Xu, and F. Huang, "Local structural changes induced by ion bombardment in magnetron sputtered ZnO: Al films: Raman, XPS, and XAS study," Surface and Coatings Technology, vol. 365, pp. 2-9, 2019.

[9] A. Pieniążek, H. Teisseyre, D. Jarosz et al., "Growth and optical properties of $\mathrm{ZnO} / \mathrm{Zn}_{1-\mathrm{x}} \mathrm{Mg}_{\mathrm{x}} \mathrm{O}$ quantum wells on $\mathrm{ZnO}$ microrods," Nanoscale, vol. 11, no. 5, pp. 2275-2281, 2019.

[10] F. Tezcan, A. Mahmood, and G. Kardaş, "Optimizing copper oxide layer on zinc oxide via two-step electrodeposition for better photocatalytic performance in photoelectrochemical cells," Applied Surface Science, vol. 479, pp. 1110-1117, 2019.

[11] B. Tian, Q. Lei, B. Tian, W. Zhang, Y. Cui, and Y. Tian, "UVdriven overall water splitting using unsupported gold nanoparticles as photocatalysts," Chemical Communications, vol. 54, no. 15, pp. 1845-1848, 2018.

[12] Q. Zhang, M. Xu, B. You, Q. Zhang, H. Yuan, and K. Ostrikov, "Oxygen vacancy-mediated $\mathrm{ZnO}$ nanoparticle photocatalyst for degradation of methylene blue," Applied Sciences, vol. 8, no. 3, p. 353, 2018.

[13] J. Wang, Z. Wang, B. Huang et al., "Oxygen vacancy induced band-gap narrowing and enhanced visible light photocatalytic activity of ZnO," ACS Applied Materials \& Interfaces, vol. 4, no. 8, pp. 4024-4030, 2012.
[14] Y. P. Xie, Y. Yang, G. Wang, and G. Liu, "Oxygen vacancies promoted interfacial charge carrier transfer of CdS/ZnO heterostructure for photocatalytic hydrogen generation," Journal of Colloid and Interface Science, vol. 503, pp. 198-204, 2017.

[15] P. Wen, Y. Sun, H. Li et al., "A highly active three-dimensional $\mathrm{Z}$-scheme $\mathrm{ZnO} / \mathrm{Au} / \mathrm{g}-\mathrm{C}_{3} \mathrm{~N}_{4}$ photocathode for efficient photoelectrochemical water splitting," Applied Catalysis B: Environmental, vol. 263, article 118180, 2020.

[16] T. Chankhanittha, J. Watcharakitti, and S. Nanan, "PVPassisted synthesis of rod-like $\mathrm{ZnO}$ photocatalyst for photodegradation of reactive red (RR141) and Congo red (CR) azo dyes," Journal of Materials Science: Materials in Electronics, vol. 30, pp. 17804-17819, 2019.

[17] D. Liu, J. Wan, H. Wang, G. Pang, and Z. Tang, "Mesoporous $\mathrm{Au} @ \mathrm{ZnO}$ flower-like nanostructure for enhanced formaldehyde sensing performance," Inorganic Chemistry Communications, vol. 102, pp. 203-209, 2019.

[18] K. A. Wong, S. M. Lam, and J. C. Sin, "Shape-controlled fabrication of $\mathrm{ZnO}$ architectures for palm oil mill effluent degradation," Journal of Nanoscience and Nanotechnology, vol. 19, no. 8, pp. 5271-5278, 2019.

[19] M. Ramzan Parra, P. Pandey, H. Siddiqui, V. Sudhakar, K. Krishnamoorthy, and F. Z. Haque, "Evolution of $\mathrm{ZnO}$ nanostructures as hexagonal disk: implementation as photoanode material and efficiency enhancement in $\mathrm{Al}$ : $\mathrm{ZnO}$ based dye sensitized solar cells," Applied Surface Science, vol. 470, pp. 1130-1138, 2019.

[20] A. Ciechan and P. Bogusławski, "Transition metal ions in $\mathrm{ZnO}$ : effects of intrashell coulomb repulsion on electronic properties," Optical Materials, vol. 79, pp. 264-268, 2018.

[21] E. G. Barbagiovanni, V. Strano, G. Franzò, I. Crupi, and S. Mirabella, "Photoluminescence transient study of surface defects in $\mathrm{ZnO}$ nanorods grown by chemical bath deposition," Applied Physics Letters, vol. 106, no. 9, article 093108, 2015.

[22] Z. Shao, Y. Wang, Y. Zhang, G. Zhu, X. Yang, and M. Zhong, "Electrochemical deposition synthesis of ZnO-NA/Cu2O-NPs type-II hierarchical heterojunction for enhanced photoelectrochemical degradation of methyl orange (MO)," Journal of Photochemistry and Photobiology A: Chemistry, vol. 364, pp. 657-670, 2018.

[23] J. X. Duan, H. Wang, and X. T. Huang, "Synthesis and characterization of $\mathrm{ZnO}$ ellipsoid-like nanostructures," Chinese Journal of Chemical Physics, vol. 20, no. 6, pp. 613-618, 2007.

[24] Z. Shao, X. Yang, G. Zhu, and M. Zhong, "Photon-induced interfacial charge transfer mechanism of porous silicon/TiO2 nanoparticles for photoelectrochemical performance," Journal of Photochemistry and Photobiology A: Chemistry, vol. 338, pp. 72-84, 2017.

[25] S. Khera and P. Chand, "Influence of different solvents on the structural, optical, impedance and dielectric properties of $\mathrm{ZnO}$ nanoflakes," Chinese Journal of Physics, vol. 57, pp. 28-46, 2019.

[26] N. Senthilkumar, M. Ganapathy, A. Arulraj, M. Meena, M. Vimalan, and I. Vetha Potheher, "Two step synthesis of $\mathrm{ZnO} / \mathrm{Ag}$ and $\mathrm{ZnO} / \mathrm{Au}$ core/shell nanocomposites: structural, optical and electrical property analysis," Journal of Alloys and Compounds, vol. 750, pp. 171-181, 2018.

[27] A. Machín, M. Cotto, J. Duconge et al., "Hydrogen production via water splitting using different Au@ZnO catalysts under UV-vis irradiation," Journal of Photochemistry and Photobiology A: Chemistry, vol. 353, pp. 385-394, 2018. 
[28] R. C. Pawar, D. H. Choi, J. S. Lee, and C. S. Lee, "Formation of polar surfaces in microstructured $\mathrm{ZnO}$ by doping with $\mathrm{Cu}$ and applications in photocatalysis using visible light," Materials Chemistry and Physics, vol. 151, pp. 167-180, 2015.

[29] M. D. L. Ruiz Peralta, U. Pal, and R. S. Zeferino, "Photoluminescence (PL) quenching and enhanced photocatalytic activity of Au-decorated $\mathrm{ZnO}$ nanorods fabricated through microwave-assisted chemical synthesis," ACS Applied Materials \& Interfaces, vol. 4, no. 9, pp. 4807-4816, 2012.

[30] X. Zhang, J. Qin, Y. Xue et al., "Effect of aspect ratio and surface defects on the photocatalytic activity of $\mathrm{ZnO}$ nanorods," Scientific Reports, vol. 4, article 4596, 2014.

[31] T. Chen, G. Z. Zhang, Z. Zhang, H. Y. Chen, and T. Wu, "Tailoring the photoluminescence of $\mathrm{ZnO}$ nanowires using Au nanoparticles," Nanotechnology, vol. 19, no. 43, article 435711, 2008.

[32] D. Tsukamoto, Y. Shiraishi, Y. Sugano, S. Ichikawa, S. Tanaka, and T. Hirai, "Gold nanoparticles located at the interface of anatase/rutile $\mathrm{TiO}_{2}$ particles as active plasmonic photocatalysts for aerobic oxidation," Journal of the American Chemical Society, vol. 134, no. 14, pp. 6309-6315, 2012.

[33] V. Ischenko, S. Polarz, D. Grote, V. Stavarache, K. Fink, and M. Driess, "Zinc oxide nanoparticles with defects," Advanced Functional Materials, vol. 15, no. 12, pp. 1945-1954, 2005.

[34] X. Zou, J. Liu, J. Su, F. Zuo, J. Chen, and P. Feng, "Facile synthesis of thermal- and photostable titania with paramagnetic oxygen vacancies for visible-light photocatalysis," Chemistry - A European Journal, vol. 19, no. 8, pp. 2866-2873, 2013.

[35] S. M. Lam, J. A. Quek, and J. C. Sin, "Mechanistic investigation of visible light responsive $\mathrm{Ag} / \mathrm{ZnO}$ micro/nanoflowers for enhanced photocatalytic performance and antibacterial activity," Journal of Photochemistry and Photobiology A: Chemistry, vol. 353, pp. 171-184, 2018.

[36] A. Tayyebi, T. Soltani, B. K. Lee, M. Outokesh, and M. Tayebi, "Novel visible light photocatalytic and photoelectrochemical (PEC) activity of carbon-doped zinc oxide/reduced graphene oxide: supercritical methanol synthesis with enhanced photocorrosion suppression," Journal of Alloys and Compounds, vol. 723, pp. 1001-1010, 2017.

[37] M. K. Choudhary, J. Kataria, and S. Sharma, "Novel green biomimetic approach for preparation of highly stable $\mathrm{Au}-\mathrm{ZnO}$ heterojunctions with enhanced photocatalytic activity," ACS Applied Nano Materials, vol. 1, no. 4, pp. 1870-1878, 2018.

[38] X. Meng, Y. Zhou, X. Zeng, X. Chen, and Y. Chu, "Oxygen vacancy mediated temperature dependent emission behavior of localized bound excitons in $\mathrm{ZnO}$ nanorods," Journal of Luminescence, vol. 195, pp. 201-208, 2018.

[39] Y. Liu, R. Wang, Z. Yang et al., "Enhanced visible-light photocatalytic activity of Z-scheme graphitic carbon nitride/oxygen vacancy-rich zinc oxide hybrid photocatalysts," Chinese Journal of Catalysis, vol. 36, no. 12, pp. 2135-2144, 2015.

[40] T. E. P. Alves, C. Kolodziej, C. Burda, and A. Franco, "Effect of particle shape and size on the morphology and optical properties of zinc oxide synthesized by the polyol method," Materials \& Design, vol. 146, pp. 125-133, 2018.

[41] C. Ton-That, L. Weston, and M. R. Phillips, "Characteristics of point defects in the green luminescence from $\mathrm{Zn}$ - and O-rich ZnO," Physical Review B, vol. 86, no. 11, p. 115205, 2012.

[42] V. Kumar, H. C. Swart, O. M. Ntwaeaborwa et al., "Origin of the red emission in zinc oxide nanophosphors," Materials Letters, vol. 101, pp. 57-60, 2013.
[43] Z. M. Liao, H. Z. Zhang, Y. B. Zhou, J. Xu, J. M. Zhang, and D. P. Yu, "Surface effects on photoluminescence of single ZnO nanowires," Physics Letters A, vol. 372, no. 24, pp. 4505-4509, 2008.

[44] H. V. Thang and G. Pacchioni, "Oxygen vacancy in wurtzite $\mathrm{ZnO}$ and metal-supported $\mathrm{ZnO} / \mathrm{M}$ (111) bilayer films ( $\mathrm{M}=$ $\mathrm{Cu}, \mathrm{Ag}$ and $\mathrm{Au})$," The Journal of Physical Chemistry C, vol. 122, no. 36, pp. 20880-20887, 2018.

[45] K. Yanome, T. Kiba, M. Kawamura et al., "Spectroscopic and photoluminescent properties of indium zinc oxide (IZO) and IZO/Ag/IZO sandwiched film," Journal of Electronic Materials, vol. 46, no. 7, pp. 3873-3879, 2017.

[46] C. Steinsiek, P. R. Shirhatti, J. Geweke, C. Bartels, and A. M. Wodtke, "Work function dependence of vibrational relaxation probabilities: NO $(\mathrm{v}=2)$ scattering from ultrathin metallic films of Ag/Au (111)," The Journal of Physical Chemistry C, vol. 122, no. 18, pp. 10027-10033, 2018.

[47] S. H. Lee, S. W. Lee, T. Oh, S. H. Petrosko, C. A. Mirkin, and J. W. Jang, "Direct observation of plasmon-induced interfacial charge separation in metal/semiconductor hybrid nanostructures by measuring surface potentials," Nano Letters, vol. 18, no. 1, pp. 109-116, 2017.

[48] Y. K. Lee, C. H. Jung, J. Park, H. Seo, G. A. Somorjai, and J. Y. Park, "Surface plasmon-driven hot electron flow probed with metal-semiconductor nanodiodes," Nano Letters, vol. 11, no. 10, pp. 4251-4255, 2011.

[49] X. Fu, G. G. Li, E. Villarreal, and H. Wang, "Hot carriers in action: multimodal photocatalysis on Au@SnO2core-shell nanoparticles," Nanoscale, vol. 11, no. 15, pp. 7324-7334, 2019.

[50] H. Lahmar, F. Setifi, A. Azizi, G. Schmerber, and A. Dinia, "On the electrochemical synthesis and characterization of $\mathrm{p}$ $\mathrm{Cu}_{2} \mathrm{O} / \mathrm{n}-\mathrm{ZnO}$ heterojunction," Journal of Alloys and Compounds, vol. 718, pp. 36-45, 2017.

[51] Y. Gong, T. Andelman, G. F. Neumark, S. O’Brien, and I. L. Kuskovsky, "Origin of defect-related green emission from $\mathrm{ZnO}$ nanoparticles: effect of surface modification," Nanoscale Research Letters, vol. 2, no. 6, pp. 297-302, 2007.

[52] N. T. Khoa, S. W. Kim, D. Van Thuan et al., "Fast and effective electron transport in a $\mathrm{Au}$-graphene- $\mathrm{ZnO}$ hybrid for enhanced photocurrent and photocatalysis," RSC Advances, vol. 5, no. 78, pp. 63964-63969, 2015. 